\title{
On the Faustian Dynamics of Policy and Political Power
}

\author{
Jinhui H. Bai* and Roger Lagunoff ${ }^{\dagger}$
}

Revised January 29, 2010

\begin{abstract}
This paper examines the Faustian dynamics of policy and power. We posit a general class of dynamic games in which current policies affect the future distribution of political power, resulting in the following "Faustian trade off": if the current ruler chooses his preferred policy, he then sacrifices future political power; yet if he wants to preserve his future power, he must sacrifice his present policy objectives. The trade-off comes from the fact that the current political ruler/pivotal voter cannot un-couple the direct effect of his policy from its indirect effect on future power.

A Policy-endogenous (PE) equilibrium describes this endogenous transfer of power, and the resulting evolution of policy and political power over time. We show that the Faustian trade-off in a $\mathrm{PE}$ equilibrium is decomposed into two basic rationales. The political preservation effect induces more tempered policy choices than if one's policy choice did not affect one's political fortunes. However, the reformation effect induces "more aggressive" policies in order to exploit the productivity gains from policies chosen by even more aggressive successors. We distinguish between political systems that give rise to monotone Faustian dynamics - political power that progressively evolves toward more fiscally liberal types of leaders, and cyclical Faustian dynamics - political power that oscillates between liberal and conservative types of leaders. In each case, we show that the Faustian trade off moderates the choices of each type of leader.
\end{abstract}

JEL Codes: C73, C61, D72, H11

Key Words and Phrases: Monotone and cyclical Faustian dynamics, policy-endogenous equilibrium, permanent authority, preservation and reformation effects, distortion-adjusted Euler equation.

\footnotetext{
*Department of Economics, Georgetown University, Washington, DC 20057, USA. Email: jb543@georgetown.edu, Phone: +1-202-687-0935, Fax: +1-202-687-6102. USA. www9.georgetown.edu/faculty/jb543/

${ }^{\dagger}$ Department of Economics, Georgetown University, Washington, DC 20057, USA. 202 687-1510. lagunofr@georgetown.edu. www9.georgetown.edu/faculty/lagunofr/lagunoff.htm.

${ }^{\ddagger}$ We thank seminar participants at CEPR Gerzensee, CIRPÉE/UQAM, Chinese University of Hong Kong, Essex, Emory, George Washington, Hong Kong, Hong Kong Science and Technology, Oregon, Peking, The Princeton Political Economy Conference, The Federal Reserve Bank of Richmond, the SED Conference, Singapore Management University, the Summer Econometric Society Meetings, Tsinghua, and UBC for their comments. We are especially grateful to Hulya Eraslan, Alessandro Riboni, Kjetil Storesletten, and three anonymous referees for their thoughtful comments and suggestions. Lagunoff gratefully acknowledges support from the National Science Foundation.
} 


\section{Introduction}

In Goethe's Faust, a well meaning Faust seeks knowledge, truth, and beauty, but cannot achieve them on his own. The devil appears and strikes a bargain with Faust: the devil will serve Faust while Faust remains here on earth; in exchange Faust must serve the devil in hell. But there is a catch. As part of the agreement, if Faust is so happy with the devil's services that he wants to "freeze" the present moment forever, Faust must then die immediately. Hence, the bargain endows Faust with the power to reach his objective but denies him the ability to savor it. ${ }^{1}$

So it is, quite often, with "political bargains." If a political leader chooses a desirable but unpopular policy, he may lose political power and thus the ability to shape policy in the future. By opting to stay in power, he sacrifices his policy objectives and then faces the same trade-off in the future. Hence, the political bargain endows a leader with the power to determine policy only as long as he does not choose the one he prefers.

These types of "Faustian trade-offs" are not uncommon in politics. In one prominent example, after signing the Civil Rights Act in 1964, President Lyndon Johnson remarked to an aid, "We have just lost the South for a generation." It proved to be a fairly accurate forecast of Democratic losses to come. ${ }^{2}$

This paper examines a dynamic game theoretic model of this "Faustian trade-off" between policy and power. To highlight the "tragic" nature of this trade off, we do not presume that rulers crave power for its own sake. Instead, political actors are assumed to be purely policymotivated. Their concern about losing power arises only because the new decision makers have different policy objectives than their own.

We model an ongoing society inhabited by a continuum of infinitely lived citizens. At each date $t$, one of the citizens, whom we refer to as the leader has effective authority to choose a policy that affects all the citizens in society. The "leader" can be viewed as an elected ruler, or alternatively, as a pivotal voter whose preferences are decisive in determining a policy. In either case, the policy choice of the leader in date $t$ can change political power in a way that ultimately changes the identity of the leader in date $t+1$. This can be done through policies that affect the underlying demographic and/or distributional characteristics of the population. For instance, an increase in a country's income tax changes the future distribution of income. In turn, this may bring about electoral changes in future political power.

\footnotetext{
${ }^{1}$ While there are many versions of the Faustian Bargain, the most well known is rendered by Goethe in (translated): Faust: The Tragedy in Two Parts, 1932 (translated in the original metres by Bayard Taylor). See also www.openlibrary.org/details/faustgoethe00goetiala

${ }^{2}$ See http://en.wikipedia.org/wiki/Lyndon_B._Johnson. We thank a referee for pointing out the reference. See also Black and Black (2002) for a detailed account.
} 
Because future political power is endogenously driven by current policy change, we refer to this as a case of policy-endogenous (PE) political power. Under policy-endogenous power, the dynamics induce a feedback loop from policy to power and back to policy. We characterize the Policy-endogenous (PE) equilibria - smooth Markov Perfect equilibria in policy-endogenous regimes. ${ }^{3}$ As a benchmark, $\mathrm{PE}$ equilibrium paths of policy and power are compared to those resulting from permanent authority $(P A)$ equilibria - equilibria under which political power is permanent.

In the PE equilibrium, a political leader faces a Faustian trade-off when his most preferred policy strips him of power and then places it in the hands of a less desirable ruler. A central theme to emerge from the study is that Faustian trade offs tend to turn political decision makers into "Burkean conservatives." That is, when facing a Faustian trade off, a leader must overcompensate for the potential loss of power by slowing the rate of political evolution as dictated by his current policy choice. This Burkean effect is compounded by the indirect effect one's decision has on the policies of future leaders: a fiscal conservative whose preferred policy might lead to an electoral loss to a moderate should worry that the moderate's choice might lead to an electoral loss to a fiscal liberal in the longer term. The result is that political shifts and policy changes are more gradual than they would be if these sorts of trade offs went unrecognized.

While an abundant literature in political economy studies the link from political power to policy, less is known about the "reverse causal link," i.e., from policy to power. One reason for this is that much of the "first generation" political economy literature studied "undistorted" political mechanisms combining standard majority voting with order-preserving policy changes in population distribution. ${ }^{4}$ In these models an individual who, for instance, is richer than another today is still expected to be richer after the policy change goes into effect. Consequently, a fixed median voter emerges in equilibrium, and so no change in political power occurs.

The traditional emphasis on "undistorted" systems is a natural starting point. Yet, biases that produce policy-endogenous distortions have, historically, been the rule rather than the exception. Until the late 19th century, most governments explicitly weighted votes by some form of wealth or property value. In democracies today the bias is less formulaic but no less real. Representation in the U.S. Senate, for example, is biased in favor of less populous states, hence toward characteristics of rural rather than urban voters. Small minority parties in parliamentary systems often have disproportionate influence in the formation of majority governments. In addition, recent studies by Benabou (2000), Campante (2007), and Bartels

\footnotetext{
${ }^{3}$ The restriction to Markov Perfection is fairly common in dynamic political games (see, for instance, Battaglini and Coate $(2007,2008)$ ). There is some justification for this, which is detailed in Section 2.

${ }^{4}$ See, for example, political economy models of growth and taxation such as Bertola (1993), Alesina and Rodrik (1994), Krusell et. al. (1996, 1997) and Krusell and Rios-Rull (1999). For a detailed review of papers in this tradition, see Krusell et al (1997) and Persson and Tabellini (2000).
} 
(2008) all document the wealth-bias implicit in the U.S. political system.

By themselves, these biases may not create a Faustian trade off. However, policy choices typically have distributional effects - changes in, say, income inequality — and we show that these effects can create a Faustian trade off when coupled with the political bias.

Something akin to a Faustian trade off arises in some recent studies of endogenous electoral outcomes. These include Besley and Coate (1998), Bourguignon and Verdier (2000), Hassler, et. al. (2003), Dolmas and Huffman (2004), Ortega (2005), Hassler, et. al. (2005), Azzimonti (2005), Campante (2007), Acemoglu and Robinson (2008). Many of these focus on way in which particular political mechanisms such as Downsian competition affect future voter preferences. These and other related papers are discussed in more detail in Section 5. We are not aware of a systemic study that identifies common features of the Faustian trade off (including the longer term indirect effects mentioned above) across a large sweep of environments and political systems. This paper builds on the recent literature by working toward that end.

We develop the model in two stages. First, we posit a stylized model of public investment in which the level of investment augments a public capital good such as infrastructure or education. We then extend the results to a general (non-parametric) model. Each model features a "detail free" mechanism by which the policy-power link is specified in reduced form as a function from population characteristics to the type or identity of the leader. This mechanism is later "endogenized" by showing that any member of the class of reduced form functions considered here can be generated by a majority voting rule in which votes are weighted by wealth or income.

We analyze both transition dynamics and steady state properties of the model. In the stylized model, the Faustian trade off moderates each leader's incentives to invest in public capital. For instance, when public capital is below its equilibrium steady state level, each leader chooses a lower level of government investment than he would if his authority were permanent. Likewise, starting above the steady state investment, a leader chooses a larger investment than if his power were permanent. As a consequence, public capital initially changes more slowly than it would in the absence of a Faustian trade off.

Yet, despite the moderating effect on individual incentives, political power does evolve over time. We distinguish between two cases: monotone and cyclical dynamics. Monotone dynamics arise in polities with a reinforcing distortion - a distortion that reinforces the natural pattern of capital accumulation. In this case, it means that an increase in public capital moves political power progressively toward more fiscally liberal types who prefer larger increases in government spending. In turn, this leads to even larger increases in spending in the future. Viewed in this way, the virtually uninterrupted increase in overall U.S. government expenditures after World-War II can be interpreted as both a cause and an consequence of a 
gradual political shift in preferences toward a greater role for government. ${ }^{5}$

By contrast, cyclical dynamics arise only in polities with countervailing distortion - a distortion that runs counter to the pattern of capital accumulation. Increases (decreases) in public capital move political power toward more fiscally conservative (liberal) leaders. This results in oscillations between liberal and conservative types. Each type's policy moves power toward the other side of the political spectrum. A natural example of this is immigration policy. Ortega (2005) presents a calibrated model of skill complementarities with a countervailing distortion. By allowing in immigrants with complementary skills, voters from one skill group endogenously increase the political opposition, since the immigrants will have opposing political preferences regarding the composition of immigration in the future.

We also compare two political institutions of differing degrees of the same type of distortion. The result is somewhat surprising. Using the monotone case to illustrate, we show that there exists a cutoff state above which the more distorted polity yields more liberal leaders, and below which it yields more conservative leaders. In other words, the more distorted polity yields a more gradual evolution of power in the short run, and a less gradual evolution in the long run. The short-run-long-run distinction is significant because it indicates that there are critical features in the transition dynamics of the Faustian model that would not be evident by focusing only on its steady state properties.

The monotone results are generalized in the non-parametric model. When certain supermodularity restrictions hold, the main results characterize Policy-endogenous equilibria in terms of a "distortion-adjusted" Euler equation in which a leader's motives may be decomposed into the following two rationales.

First, the "political preservation effect" turns all leaders into Burkean conservatives regardless of political preference. That is, each leader chooses more moderately/less aggressively than he would if he did not face a Faustian trade off. Roughly, the political preservation effect represents the distortion in the current leader's incentives due to the effect his policy choice has on the identities of future leaders. Because policy preferences across individuals differ, each distinct leader determines a distinct policy rule. Hence a change in current policy alters the trajectory of policy rules (rather than just the policies). The larger the wedge between current and future leaders' preferences, the greater the distortion. As a result, today's leader slows the rate of political change with his policy choice. We show that the preservation effect on a given individual's incentives increases in magnitude through time.

Yet, the preservation effect is partly offset by a second rationale, the "reformation effect," which represents the distortion in the current leader's incentives due to the effect his policy choice has on policies (rather than policy rules) chosen in the subsequent period. The reformation effect isolates the effect of current policy on next period's productivity by ignoring

\footnotetext{
${ }^{5}$ See Peltzman (1980), Husted and Kenny (1997), and Lott and Kenny (1999).
} 
the changes to future policy rules themselves. Looking just at productivity, a more aggressive policy choice in the subsequent period increases the marginal productivity of policies in the present. In short, the reformation effect pushes the current leader toward a more aggressive policy choice.

While the preservation and reformation effects refer to distorted incentives of a fixed decision maker, it is important to remember that decision authority changes hands over time. The overall effect is that power evolves toward more progressive leaders, and, in fact, the policy trajectory is more progressive than under permanent authority in the long run. The steady state stock is larger and the leader more progressive, than in a case of no Faustian trade offs.

The general model is introduced in Section 2. Section 3 elaborates on the parametric model. The model displays some of the salient features of political systems that gives rise to policy-endogenous power. Section 4 returns to the abstract model and contains the main decomposition result. Section 5 examines the related literature and examples. Finally, Section 6 discusses various extensions. The proofs are contained in an Appendix at the end.

\section{The Basic Setup}

In this Section, we describe a general model in which Faustian tradeoffs occur. The level of generality underscores the fact that policy endogenous political change is not necessarily an isolated feature of a small set of environments. However, for concreteness a special case of the general model is presented in Section 3 in the form of a stylized model of public sector investment and growth.

\subsection{The Environment}

At each date $t=0,1,2, \ldots$ a government must undertake a policy decision that affects all members of society. The policy interacts with a state variable that fully summarizes the economy at that date. Let $a_{t}$ denote the policy choice and $\omega_{t}$ the state. Feasible policies and states are restricted to compact intervals.

The state is assumed to evolve according to a deterministic Markov process determining the future state as a function of current states and actions. The transition function $Q$ is assumed smooth, nondecreasing in $\omega_{t}$, increasing in $a_{t}$, and jointly concave in the pair $\omega_{t}$ and $a_{t}$.

Society is comprised of continuum $I=[0,1]$ of infinitely lived citizen-types. Given any 
sequence of states $\left\{\omega_{t}\right\}$ and policies $\left\{a_{t}\right\}$, the dynamic payoff to citizen-type $i \in I$ is

$$
\sum_{t=0}^{\infty} \delta^{t} u\left(i, \omega_{t}, a_{t}\right)
$$

where $\delta$ is a common discount factor, and the payoff function $u$ is smooth, increasing in $\omega_{t}$, decreasing and strictly concave in $a_{t}$, and jointly concave in the pair $\omega_{t}$ and $a_{t}$.

The assumptions on $u$ and $Q$ reflect the idea that the policy $a_{t}$ is a tax or public investment that, while costly in the present, augments the future value of the state. In turn, the state $\omega_{t}$ is a parameter that determines a capital stock or income distribution. An obvious example is an income tax that generates revenue to fund public infrastructure.

\subsection{The Permanent Authority Benchmark}

Consider a benchmark case of a decision maker who faces no Faustian trade-off. There are a few ways this can happen. For instance, if all individuals have identical preferences over policy, then a purely policy-motivated type is indifferent between retaining and losing political power. Alternatively, an individual can lose power for purely exogenous reasons unrelated to his current policy choice.

The most natural benchmark, however, is that of an individual who maintains political power regardless of his policy action. This "king" or "dictator," whom we label $i_{0}$, chooses a policy $a_{t}$ at each date $t$, fully anticipating that his authority is perpetual. We refer to this as the permanent authority (PA) regime. PA regimes are not, almost by definition, common in modern democracies. They were common, however, in many European monarchies prior to the 20th century.

The PA regime can also be interpreted normatively as a time-consistent social planner. In our model, there is no qualitative difference between the permanent authority of a fixed citizen-type, and the authority of a social planner who aggregates payoffs across citizen-types. Significantly, most political economy models either assume explicitly a PA regime (e.g., a social planner) or derive one in equilibrium under special assumptions on preferences, technology, and political institutions.

Consider the problem of a permanent authority $i_{0}$. His policy choices are characterized by a policy function $\psi\left(\omega_{t}\right)=a_{t}$ (omitting the notational dependence on $i_{0}$ ) that solves the Bellman equation

$$
V\left(i_{0}, \omega_{t} ; \psi\right)=\max _{a_{t}}\left[u\left(i_{0}, \omega_{t}, a_{t}\right)+\delta V\left(i_{0}, \omega_{t+1} ; \psi\right)\right]
$$

subject to $\omega_{t+1}=Q\left(\omega_{t}, a_{t}\right)$. We refer to the function $\psi$ that solves $(2)$ as a Permanent 
Authority (PA) equilibrium. The PA equilibrium serves as a baseline for comparison. ${ }^{6}$

\subsection{Policy-Endogenous Political Power}

We compare the PA regime in which there are no Faustian trade offs to one in which there are. In an environment with policy endogenous (PE) political power, the current policy choices induce changes in future political power. To focus on decision-theoretic aspects, political power is modeled in reduced form by assuming that each period the political system produces an outcome that is rationalized by the preferences of a pivotal individual. This individual (e.g., pivotal voter or political leader) is, in effect, endowed with the exclusive right in period $t$ to choose the policy action $a_{t}$. The assumption that the political process admits a pivotal leader clearly involves some loss of generality. There are, however, commonly known conditions on policy preferences, notably the class of intermediate preferences (Grandmont (1978)), and preferences satisfying single crossing properties (Gans and Smart (1996) and Rothstein (1990)) that do admit pivotal voters.

Henceforth, we refer to the pivotal decision maker as the leader. Political power is therefore represented by a mapping from states (e.g., capital stocks, income distributions) to citizentypes. Formally, the mapping is assumed to be a smooth, weakly monotone function $\mu: \omega \mapsto i$ such that $i_{t}=\mu\left(\omega_{t}\right)$ is the leader who decides on policy in state $\omega_{t}$.

Because $\mu$ determines "who's in charge" in each state, we refer to it as the authority function. The key attribute of an authority function, for our purposes, is that it admits the possibility that political power changes endogenously due to changes in the state. Current policy changes produce changes in the state which, in turn, produce changes in the identity of the leader through $\mu$.

To facilitate a comparison with the PA regime, we fix $i_{0}$ as both the permanent authority and the initial decision maker under policy-endogenous power. The change in the identity of the leader, as described by $\mu$, defines a dynamic game with a potentially infinite set of players. The players' choices result in a stationary Markov process that realizes states $\left\{\omega_{0}, \omega_{1}, \omega_{2}, \ldots,\right\}$, leaders $\left\{i_{0}, i_{1}, i_{2}, \ldots,\right\}$, and policies $\left\{a_{0}, a_{1}, a_{2}, \ldots\right\}$. We refer to these processes as the Faustian dynamics of PE political power.

In much of the paper, $\mu$ is treated as exogenous, although we give an explicit micro foundation for it in Section 3. In the simplest case of majority voting, $\mu\left(\omega_{t}\right)$ is the median type whenever the Median Voter Theorem holds. However, in order to obtain a state-dependent

\footnotetext{
${ }^{6}$ Implicitly, the PA equilibrium characterizes a time consistent optimal strategy for $i_{0}$ if the private sector's dynamic response is Markov or is absent altogether. In the case where the private sector is absent, the PA equilibrium amounts to a single agent dynamic programming problem, in which case it coincides with the full commitment solution.
} 
authority function $\mu$, votes in some cases may need to be weighted by, say, wealth or income. The idea roughly is that changes in the state "distort" the income distribution, and wealthweighted voting is sensitive to these types of distortions - see Section 3 for an explicit description of such a voting mechanism.

This sensitivity of voting to changes in the wealth distribution could be explicitly built in to the polity as in the case of the U.S. Senate or in Germany in the 19th century. In other cases, the sensitivity is implicit such as when a citizen's political influence depends on his wealth. ${ }^{7}$ Hence, policy changes such as tax cuts may change the identity of the pivotal voter in a heterogeneous economy if campaign contributions affect the outcome of an election. Alternatively, changes in immigration laws, education levels, or fertility policy can have (longer run) electoral effects even under ordinary median voter rules, since the demographic changes themselves may be biased toward the participation of certain groups or social classes. For example, Tichenor (2002) describes 19th century immigration policy in the U.S., sometimes restrictive but more often expansive, that ultimately brought about large political shifts toward urban regions that came to be reflected in congressional and presidential elections.

Under PE power generally, the leader $i_{t}=\mu\left(\omega_{t}\right)$ in period $t$ chooses an action $a_{t}$ anticipating the effect that it has on the future trajectory of states, leaders, and policies. A Policy-Endogenous (PE) equilibrium is defined as a Markov Perfect equilibrium in the PE environment. More precisely, a PE equilibrium, denoted by $\Psi^{*}$, is a Markov policy function (with $\Psi^{*}\left(\omega_{t}\right)=a_{t}$ ) such that $\Psi^{*}$ is a best response by citizen-type $i$ against any historycontingent strategy that differs from $\Psi^{*}$ only in states $\omega$ for which $\mu(\omega)=i{ }^{8}$ Under $\Psi^{*}$, the continuation payoff to a citizen-type $i$ is given by

$$
V\left(i, \omega_{t} ; \Psi^{*}\right)=\sum_{\tau=t}^{\infty} \delta^{\tau-t} u\left(i, \omega_{\tau}, \Psi^{*}\left(\omega_{\tau}\right)\right)
$$

given the sequence $\left\{\omega_{t}\right\}$ induced by transition function $Q$. A standard argument shows that the so-called one-shot deviation principle applies to $\mathrm{PE}$ equilibria. Namely, $\Psi^{*}$ is a PE equilibrium if and only if for all $\omega_{t}$, and for all $a_{t}$,

$$
V\left(\mu\left(\omega_{t}\right), \omega_{t} ; \Psi^{*}\right) \geq u\left(\mu\left(\omega_{t}\right), \omega_{t}, a_{t}\right)+\delta V\left(\mu\left(\omega_{t}\right), Q\left(\omega_{t}, a_{t}\right) ; \Psi^{*}\right)
$$

Clearly, there are other types of Subgame Perfect equilibria one might examine in a Faustian model. However, we think the restriction to Markov Perfection is sensible in this context.

${ }^{7}$ Polities that weight votes by wealth, at least implicitly, are not exotic. Benabou (2000), Bartels (2008), and Campante (2007) all provide evidence of bias toward the affluent in U.S. electoral politics. They show that campaign contributions (Campante) or differential turnout rates (Benabou, Bartels) produce roughly the same effect as if the votes were weighted by wealth.

${ }^{8}$ To be clear, it should be noted that Markov Perfect equilibria can be alternatively described as Subgame Perfect equilibria in Markov strategies. This means that feasible strategies and payoffs, fully described, may possibly vary with the entire history. For brevity, however, we omit the full description of such strategies and payoffs and limit our description to payoffs evaluated by equilibrium (Markov) stategies. 
First, it facilitates a direct comparison with the permanent authority equilibrium in (2). Second, the restriction seems natural in large populations. Costs of coordination are presumably higher in larger economies, and so strategies that therefore depend only on the current, payoff relevant state may reduce these costs. Third, if policy-makers have uniformly bounded recall then it can be shown that any Subgame Perfect equilibrium in our model must be Markov. ${ }^{9}$

Given a PE equilibrium $\Psi^{*}$, consider what policy would have been chosen in state $\omega_{t}$ by an arbitrary citizen-type $i$ ? This question is hypothetical because an arbitrary $i$ is not the authority in state $\omega_{t}$ unless it happens that $i=i_{t}=\mu\left(\omega_{t}\right)$. The question is important nevertheless because it allows one to compare the Faustian incentives for different political types in any situation. Let $a_{t}=\Psi\left(i, \omega_{t}\right)$ denote the hypothetical decision of type $i$. Call $\Psi$ a hypothetical equilibrium if for all $\omega_{t}$, all $i$ and all $a_{t}$

$$
u\left(i, \omega_{t}, \Psi\left(i, \omega_{t}\right)\right)+\delta V\left(i, Q\left(\omega_{t}, \Psi\left(i, \omega_{t}\right)\right) ; \Psi^{*}\right) \geq u\left(i, \omega_{t}, a_{t}\right)+\delta V\left(i, Q\left(\omega_{t}, a_{t}\right) ; \Psi^{*}\right)
$$

The inequality in (5) coincides with (4) in those states for which $i=\mu\left(\omega_{t}\right)$. The hypothetical equilibrium and the PE equilibrium are therefore related by $\Psi\left(\mu\left(\omega_{t}\right), \omega_{t}\right)=\Psi^{*}\left(\omega_{t}\right)$.

Hence, starting from initial state $\omega_{0}$, the decision maker $i_{0}$ chooses $\Psi\left(i_{0}, \omega_{0}\right) \equiv \Psi^{*}\left(\omega_{0}\right)$. Type $i_{0}$ correctly anticipates that his chosen policy $a_{0}$ leads to a possible change in decision authority at date $t=1$. This change is given by $i_{1}=\mu\left(\omega_{1}\right)$ where next period's state $\omega_{1}$ is determined by $\omega_{1}=Q\left(\omega_{0}, \Psi^{*}\left(\omega_{0}\right)\right)$. It is generally true that $\Psi\left(i_{0}, \omega_{1}\right) \neq \Psi^{*}\left(\omega_{1}\right)$ because $i_{0}$ no longer makes the decision in state $\omega_{1}$ in the PE equilibrium, and the decision type $i_{1}$ will generally have different preferences over policy. The more interesting comparison, however, is between $\Psi\left(i_{0}, \omega_{1}\right)$ and $\psi\left(\omega_{1}\right)$. It tells us how an arbitrary citizen-type would react to the loss of power in a given state, where the extent of the loss is determined by that state.

In certain instances, the current leader faces no Faustian trade-off even when $\mu$ is distortionary. For instance, suppose that period payoffs are of the form $u(i, \omega, a)=u_{1}(i)+u_{2}(\omega, a)$ or the form $u_{1}(i) u_{2}(\omega, a)$. In either case, the additive or multiplicative separability implies that individual-specific characteristics do not affect policy preferences. Individuals' policy preferences are therefore the same, and so changes in power have no effect on policy.

\section{A Stylized Model of Public Sector Investment}

This Section examines how Faustian dynamics work in a concrete, special case of the general model. We examine a stylized model of public sector investment where political authority is

\footnotetext{
${ }^{9}$ An economy has uniformly bounded recall if there is a finite bound $m$ such that every decision maker's memory of the past history cannot exceed $m$ periods back. The argument for the stated assertion relies on asynchronous decision making, which applies to the present model. A simple proof is found in Bhaskar and Vega-Redondo (2002).
} 
derived explicitly from a system of weighted voting. We examine two cases. One where the public sector expands monotonically as political power steadily evolves toward more fiscally liberal types. The other where public sector alternately expands and contracts and political power oscillates between fiscally liberal and conservative types of decision makers. We use the model to illustrate effects of Faustian dynamics on the evolution of political power, public sector growth, and income inequality.

\subsection{The Environment}

Society invests each period in a public capital good (infrastructure) which is produced according to the linear transition

$$
\omega_{t+1}=Q\left(\omega_{t}, a_{t}\right)=(1-d) \omega_{t}+a_{t}
$$

Here, $\omega_{t}$ is the current stock of public capital, $a_{t}$ is public investment, and $d \in(0,1]$ is the depreciation rate. Public investment $a_{t}$ is produced from a lump sum tax $\mathcal{T}_{t}$, according to a concave production technology $a_{t}=\left(2 \mathcal{T}_{t}\right)^{1 / 2}$. This technology can be alternatively expressed as the cost $\mathcal{T}_{t}=\frac{1}{2} a_{t}^{2}$ of providing public investment $a_{t}$.

Each citizen is assumed to provide labor inelastically with a time allocation normalized to one. His labor is combined with public capital to produce income

$$
y\left(i, \omega_{t}\right)=g(i)+f(i) \omega_{t}
$$

with $g(i)$ and $f(i)$ denoting type $i$ 's efficiency utilization of labor and capital, respectively. We assume that $f^{\prime} \geq 0$, so that higher types have (weakly) higher efficiency utilization of public capital.

A citizen's flow payoff is assumed to be linear in his consumption, and we assume (without loss of generality, due to the linear payoff) that there is no private borrowing or saving. A citizen therefore consumes his after-tax income $y\left(i, \omega_{t}\right)-\mathcal{T}_{t}$. His flow payoff is then given by

$$
u=y\left(i, \omega_{t}\right)-\mathcal{T}_{t}=g(i)+f(i) \omega_{t}-\frac{a^{2}}{2}
$$

Dropping the labor efficiency term $g(i)$ yields an indirect utility function of the form in $(1)$, given by

$$
u\left(i, \omega_{t}, a_{t}\right)=f(i) \omega_{t}-\frac{a_{t}^{2}}{2} .
$$

Notice that the idiosyncratic labor productivity $g(i)$ drops out of $(7)$ as it plays no role in citizen $i$ 's policy preference. However, $g(i)$ will play an indirect role in the evolution of the economy through its effect on the political process. 


\subsection{A Voting Foundation for $\mu$}

The stylized model has a natural political interpretation. The state $\omega$ may be regarded as a proxy for the size of government. Hence, the assumption $f^{\prime} \geq 0$ implies that the dynamic policy preferences are well ordered: higher types are more "fiscally liberal" in the sense that they prefer a larger public sector. ${ }^{10}$ Given preferences satisfying (7), one can show that the Median Voter Theorem applies. Hence, any voting system, regardless of the way in which votes are weighted admits a pivotal voter whose preferred policy choice beats any other in a pairwise comparison.

One such voting system is that of wealth-weighted voting discussed in Section 2. Specifically, consider a polity that allocates $y\left(i, \omega_{t}\right)$ votes to each type $i$ in state $\omega_{t}{ }^{11}$ Then, applying the Median Voter Theorem (where "median" is wealth-weighted here), the authority function $\mu(\omega)$ is endogenously determined by

$$
\frac{\int_{0}^{\mu\left(\omega_{t}\right)} y\left(i, \omega_{t}\right) d i}{\int_{0}^{1} y\left(i, \omega_{t}\right) d i}=\frac{\int_{0}^{\mu\left(\omega_{t}\right)}[g(i)+f(i) \omega] d i}{\int_{0}^{1}[g(i)+f(i) \omega] d i}=\frac{1}{2}
$$

Hence, while order-preserving shifts in the wealth distribution do not change the median voter, they do change the wealth-weighted pivotal voter. In this case, $\mu$ increases (decreases) whenever Lorenz inequality increases (decreases) in the state $\omega_{t}$.

An authority function $\mu$ can therefore be computed from (8) given functions $f$ and $g$. A particularly tractable form of $\mu$, given by

$$
i_{t}=\mu\left(\omega_{t}\right)=\frac{\kappa_{0}+\kappa \omega_{t}}{\kappa_{0}+\kappa \omega_{t}+1}
$$

with parameters $\kappa$ and $\kappa_{0}>0$, may be obtained from a marginal efficiency $f$ satisfying: $f(i)=\frac{i}{1-i}$ for all $i \leq \bar{i}$, and $f(i)=f(\bar{i})$ for all $i \geq \bar{i}$. The marginal labor efficiency $g$ can easily be backed out using (8). The details are contained in a technical appendix. ${ }^{12}$

For the purposes of solving the model, the most relevant property of this construction is that for all $\omega_{t}$,

$$
f\left(\mu\left(\omega_{t}\right)\right)=\kappa_{0}+\kappa \omega_{t}
$$

\footnotetext{
${ }^{10}$ To see this, observe that when flow payoffs satisfy (7), the value function is an affine function of $f(i)$ regardless of the policy function $\Psi^{*}$ :

$$
V\left(i, \omega_{t} ; \Psi^{*}\right)=f(i) V^{1}\left(\omega_{t} ; \Psi^{*}\right)+V^{2}\left(\omega_{t} ; \Psi^{*}\right) .
$$

${ }^{11}$ In general, we could have considered any weighting system that places positive weight on one's income/wealth. See Footnote 7 for real world examples.

${ }^{12}$ See www9.georgetown.edu/faculty/lagunofr/onlineappendix.pdf.
} 
In other words, authority is given to the type $i_{t}$ for whom the marginal value of public sector capital is an affine function of the stock itself. Increases in the stock therefore correspond to more fiscally liberal authorities (for $\kappa>0$ ). By varying parameters $\kappa$ and $\kappa_{0}$ such that all authority functions intersect the initial point $\left(\omega_{0}, i_{0}\right)$, Equation $(9)$ maps out a one-dimensional class of authority functions, each of which differs by the adjustment speed and direction of political power. ${ }^{13}$

Figure 1 illustrates three examples of authority functions that satisfy (9). In the Figure, $\mu^{\circ}, \mu^{\prime}$, and $\mu^{\prime \prime}$ correspond to parameter values for $\kappa=0, \kappa^{\prime}, \kappa^{\prime \prime}$, respectively, where $0<\kappa^{\prime}<\kappa^{\prime \prime}$. The special case of $\kappa=0$ corresponds to the "undistorted" case of permanent authority, with $i_{0}$ as the permanent leader. Clearly there is no Faustian trade-off for $i_{0}$ in this case. When $\kappa=0$, it is not hard to show that the PA equilibrium is state-invariant: $\psi\left(\omega_{t}\right)=\bar{\psi} \cdot{ }^{14}$

The value $|\kappa|$ measures the degree of institutional distortion. An increase in $|\kappa|$ (while adjusting $\kappa_{0}$ to keep the same initial point) implies faster structural evolution of political authority. In the Figure, $\mu^{\prime}$ and $\mu^{\prime \prime}$ both begin with $i_{0}$ as the initial decision maker. The function $\mu^{\prime}$ is "less distorted" than $\mu^{\prime \prime}$ in the sense that $\mu^{\prime \prime}$ offers a starker Faustian trade-off for leader $i_{0}$. Intuitively, one might call $\mu^{\prime}$ more "conservative" in the "Burkean" sense of offering a more gradual structural evolution of political power; $\mu$ " is more "progressive" in the sense of inducing accelerated change. A central feature of the Faustian model, as we later show, is that equilibrium responses of individuals may undercut this seemingly straightforward comparison: the more conservative rule does not always produce a more gradual evolution of political authority in equilibrium.

In either case, $\kappa>0$ implies that $\mu$ is increasing. An increase in public sector capital therefore adjusts political power upward toward more fiscally liberal types - those with higher marginal value of government expenditure. But more liberal types choose higher levels of government expenditure which increase the public capital stock. In this sense, $\mu$ represents a reinforcing distortion. If instead, $\kappa<0$, then an increase in public capital would adjust political power downward, toward the more conservative "small government" types. In that case, because the authority function $\mu$ moves in opposition to the transition technology, it represents a countervailing distortion.

\footnotetext{
${ }^{13}$ This class of authority functions are those that satisfy $\mu\left(\omega_{t}\right)=f^{-1}\left(\kappa_{0}+\kappa \omega_{t}\right)$ such that $\kappa$ and $\kappa_{0}$ satisfy the linear equation $f\left(i_{0}\right)=\kappa_{0}+\kappa \omega_{0}$.

14 Because $f(i)$ is a monotone function, the Permanent Authority equilibrium can be identified as a solution to a social planner's problem. To see this, suppose that $h$ is a density on $[0,1]$ in which $h(i)$ is the welfare weight assigned to citizen-type $i$. Then there exists $i_{0}$ such that

$$
f\left(i_{0}\right)=\int h(i) f(i) d i
$$

In other words, the social welfare function coincides with the utility function of a specially chosen $i_{0}$. Therefore, the social planner's problem is the same as the PA problem with permanent authority vested in type $i_{0}$.
} 


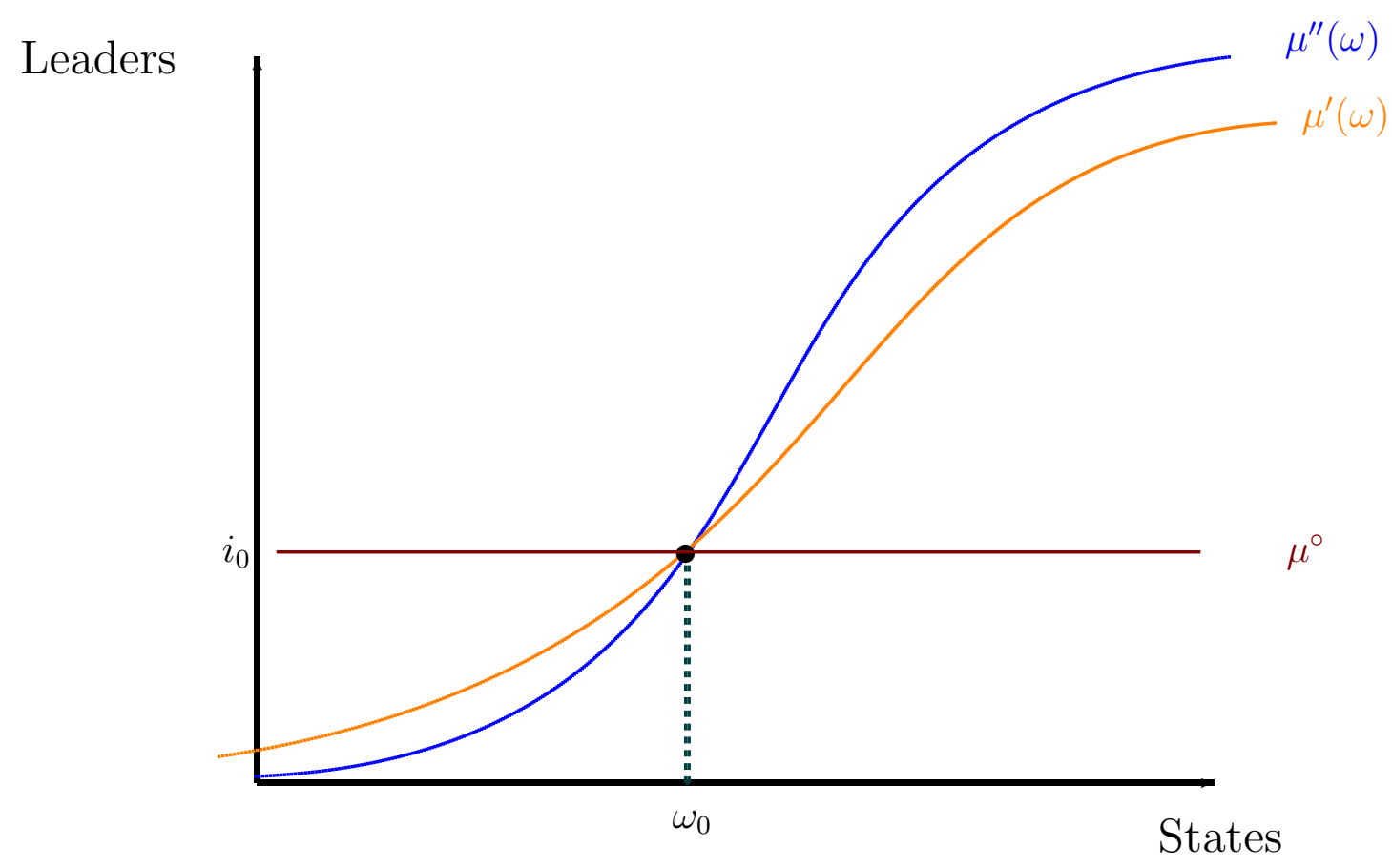

Figure 1: Authority Functions in the Policy-Endogenous and Permanent Power Regimes

\subsection{Monotone Faustian Dynamics}

Consider first the case of $\kappa>0$, thus a reinforcing distortion. Since $\mu$ slopes upward, increases in public capital put power in the hands of more fiscally liberal leaders. In the following result, $\psi$ refers to the state-invariant Permanent Authority (PA) equilibrium.

Proposition 1 Consider any authority function $\mu$ satisfying (9). If $0<\kappa<d\left(\frac{1}{\delta}-1+d\right)$, then the following hold.

(i) There exist an increasing, affine Policy-Endogenous (PE) equilibrium policy rule $\Psi^{*}\left(\omega_{t}\right)$ and a nonincreasing, affine Hypothetical rule $\Psi\left(i_{0}, \omega_{t}\right)$, each of which are unique in the corresponding class of affine equilibria.

(ii) The PE equilibrium path of states $\left\{\omega_{t}\right\}$ converges monotonically to a unique steady state $\omega^{*}=Q\left(\omega^{*}, \Psi^{*}\left(\omega^{*}\right)\right)$. If $\omega_{0}<\omega^{*}$, then $\omega_{0}<\omega_{t}$ implies $\Psi\left(i_{0}, \omega_{t}\right)<\psi\left(\omega_{t}\right)$ and $\Psi\left(i_{0}, \omega_{t}\right)<$ $\Psi^{*}\left(\omega_{t}\right)$. Whereas if $\omega_{0}>\omega^{*}$, then $\omega_{t}<\omega_{0}$ implies $\Psi\left(i_{0}, \omega_{t}\right)>\psi\left(\omega_{t}\right)$ and $\Psi\left(i_{0}, \omega_{t}\right)>$ $\Psi^{*}\left(\omega_{t}\right)$. 
(iii) If $\omega_{0}<\omega^{*}$, then there exists a state $\hat{\omega}$ with $\omega_{0}<\hat{\omega}<\omega^{*}$ such that

$$
\begin{array}{ll}
\Psi^{*}\left(\omega_{t}\right)<\psi\left(\omega_{t}\right) & \forall \omega_{0} \leq \omega_{t}<\hat{\omega} \\
\Psi^{*}\left(\omega_{t}\right)>\psi\left(\omega_{t}\right) & \forall \omega_{t}>\hat{\omega}
\end{array}
$$

whereas if $\omega_{0}>\omega^{*}$, then there exists a state $\hat{\omega}$ with $\omega^{*}<\hat{\omega}<\omega_{0}$ such that

$$
\begin{array}{ll}
\Psi^{*}\left(\omega_{t}\right)>\psi\left(\omega_{t}\right) & \forall \hat{\omega}<\omega_{t} \leq \omega_{0} \\
\Psi^{*}\left(\omega_{t}\right)<\psi\left(\omega_{t}\right) & \omega_{t}<\hat{\omega}
\end{array}
$$

The upper bound on $\kappa$ is required to satisfy a transversality condition that bounds the rate of growth. The Proof in the Appendix shows that the policy function of the affine form $\Psi^{*}\left(\omega_{t}\right)=(d-K) \omega^{*}+K \omega_{t}$ where $K$ is a constant (in $\left.\omega_{t}\right)$ with $0 \leq K<d$, and $\omega^{*}$ is the unique steady state. The coefficients implicitly vary in the exogenous parameters $\kappa_{0}, \kappa, \delta$, and depreciation rate $d$.

Parts (ii) and (iii) state what will turn to be quite general properties of Faustian dynamics. Part (ii) compares the Hypothetical rule to both the PE and PA rules. If the initial state is below the steady state, then political power evolves from fiscally conservative toward more fiscally liberal types. By choosing a smaller expansion in government expenditures than he would if his power were permanent, type $i_{0}$ slows the rate of political change as it evolves away from his type. In this sense fiscal conservatism coincides with "Burkean" conservatism.

By contrast, when the initial state is above the steady state, then political power evolves from fiscally liberal toward fiscally conservative types. In that case, type $i_{0}$, a fiscal liberal, acts as a Burkean conservative by choosing a larger expansion in government expenditures than he would if his power were permanent. By doing so, he once again slows the rate of political change.

For purposes of intuition, we restrict our discussion and pictures to the case of $\omega_{0}<$ $\omega^{*}$. Then the (hypothetical) policies of leader $i_{0}$ become more conservative over time/states because more distant types assume power as the state progresses upward. But, as Part (iii) shows, individual caution is juxtaposed with progressive evolution of policy. The PolicyEndogenous equilibrium starts out more conservative than Permanent Authority, but winds up more fiscally liberal in long run. The intuition is as follows. Consider the incentives of the initial leader $i_{0}$. He anticipates a growing economy under $\Psi^{*}$. However, $i_{0}$ also anticipates the corresponding shift of power to more liberal types in the future. Because the higher tax rates chosen by these liberal types are undesirable from $i_{0}$ 's viewpoint, $i_{0}$ slows the process of political evolution toward these types by choosing a lower tax rate than even he himself would want. The fact that $\Psi\left(i_{0}, \omega_{t}\right)$ is decreasing in the state demonstrates, in fact, that the incentive to "slow things up" intensifies the larger is the public sector. This is seen in the first diagram in Fig. 2. The second diagram displays transition dynamics using the notation 

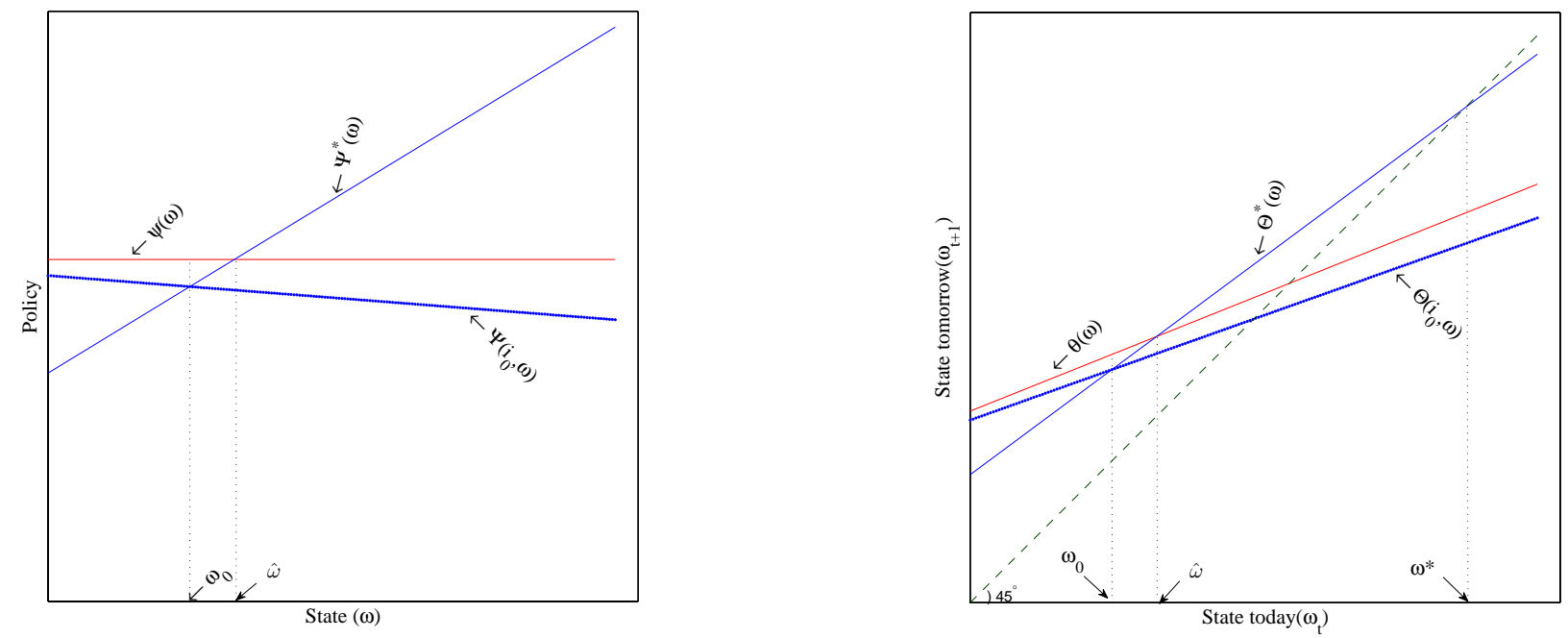

Figure 2: Monotone Policy Functions \& Monotone Transition Dynamics in the PE and PA Equilibria.

$\theta\left(\omega_{t}\right)=Q\left(\omega_{t}, \psi\left(\omega_{t}\right)\right)$ for PA, $\Theta^{*}\left(\omega_{t}\right)=Q\left(\omega_{t}, \Psi^{*}\left(\omega_{t}\right)\right)$ for PE, and $\Theta\left(i_{0}, \omega_{t}\right)=Q\left(\omega_{t}, \Psi\left(i_{0}, \omega_{t}\right)\right)$ for Hypothetical PE, respectively.

This "Faustian" motive for gradualism described above can be identified in the leader's Euler equation. Using the parametric assumptions, the value function for the current leader $i_{t}$ (but not for an arbitrary $i$ ) is

$V\left(i_{t}, \omega_{t} ; \Psi^{*}\right)=\max _{a_{t}}\left\{f(i) \omega_{t}-\frac{a_{t}^{2}}{2}+\delta V\left(i, \omega_{t+1} ; \Psi^{*}\right)\right\}$ subject to $\omega_{t+1}=(1-d) \omega_{t}+a_{t}$

If $\Psi^{*}\left(\omega_{t}\right)$ lies in the interior of the feasible policy space, then it satisfies the first-order condition $^{15}$

$$
0=-\Psi^{*}\left(\omega_{t}\right)+\delta D_{\omega_{t+1}} V\left(i_{t},(1-d) \omega_{t}+\Psi^{*}\left(\omega_{t}\right) ; \Psi^{*}\right) .
$$

The first term is clearly the marginal cost of an increase in government spending, while the second is the discounted marginal benefit in the future. Consider next period's decision from the point of view of the current decision maker $i_{t}$. Since next period's decision maker $i_{t+1}$ is different from $i_{t}$, the decision next period induces a marginal distortion away from $i_{t}$ 's optimal policy choice in $t+1$. This distortion is given by

$$
\Delta\left(i_{t}, \omega_{t+1} ; \Psi^{*}\right)=-\Psi^{*}\left(\omega_{t+1}\right)+\delta D_{\omega_{t+2}} V\left(i_{t},(1-d) \omega_{t+1}+\Psi^{*}\left(\omega_{t+1}\right) ; \Psi^{*}\right) .
$$

Notice that the right-hand side of (12) is of the same form as (11), shifted one period ahead. Intuitively, because the government's capital stock $\omega_{t}$ increases, power shifts toward policy

\footnotetext{
${ }^{15}$ Throughout the paper, the partial derivative of a function $F(x, y)$ is expressed as $D_{x} F$.
} 
makers who prefer higher levels of government spending. Hence, $\Delta\left(i_{t}, \omega_{t+1} ; \Psi^{*}\right)<0$ since $i_{t+1}$ chooses a higher level of spending than $i_{t}$ himself would choose in state $\omega_{t+1}$.

Differentiating the value function $V$ in (10), substituting in the distortion equation (12), and iterating one period, the discounted marginal benefit $D_{\omega_{t+1}} V\left(i_{t}, \omega_{t+1} ; \Psi^{*}\right)$ of an increase in current investment can now be expressed as

$$
D_{\omega_{t+1}} V\left(i_{t}, \omega_{t+1} ; \Psi^{*}\right)=\left[f\left(i_{t}\right)+(1-d) \Psi^{*}\left(\omega_{t+1}\right)\right]+\left[(K+1-d) \Delta\left(i_{t}, \omega_{t+1} ; \Psi^{*}\right)\right]
$$

The marginal continuation value $D_{\omega_{t+1}} V$ can be decomposed into two effects. The first bracketed term $[\cdot]$ on the right-hand side describes the direct effect that current policy has on next period's state. This term also exists (is non-zero) under permanent authority, although the particular values differ between the two regimes. We refer to this difference (between PE and PA) as the reformation effect since it describes the net direct incentive to increase public investment via changes in the marginal value of public sector capital. The reformation effect does not include the "Faustian" distortion in incentives due to endogenous change in future leadership. This distortion is captured by the second bracketed term [·]. This term exists only in policy-endogenous decision problems. This distortion creates the "Burkean" incentive by all leaders to slow the evolution of political power as it moves away from the current leader. This is seen by the fact $\Delta\left(i_{t}, \omega_{t+1} ; \Psi^{*}\right)<0$. Hence, we refer to it as the political preservation effect. General properties of both these effects are described in the next Section.

Consider the decision of $i_{0}$ at date 0 . His PE policy may be well below his PA policy, and it takes time before the PE path overtakes that of permanent authority. Part (iii) shows that this eventually happens (see Fig. 2). For $\omega_{t}$ close to $\omega_{0}$, the leader-type $i_{t}$ is not so different from $i_{0}$, and so the preference for conservative change may place $\Psi^{*}\left(\omega_{t}\right)$ below $\psi\left(\omega_{t}\right)$ for a time.

Notice finally that the Faustian dynamics of states and leaders also moves monotonically. To see this, observe that if $\omega_{0}$ is close to zero, it lies below the steady state. Hence, the equilibrium state transition $\Theta^{*}\left(\omega_{t}\right) \equiv Q\left(\omega_{t}, \Psi^{*}\left(\omega_{t}\right)\right)$ is increasing in the state, and, consequently, the equilibrium paths $\left\{\omega_{t}\right\}$ and $\left\{i_{t}\right\}$ are increasing. This is illustrated in the second diagram in Fig. 2 which displays the comparison between the PE transition $\Theta^{*}$, the hypothetical transition $\Theta$, and the PA transition $\theta$.

So far, we have compared the PE to the PA regime. But this comparison can be applied to any two PE political institutions, one yielding more gradual change in political power than the other. This was illustrated in Figure 1.

Proposition 2 Consider two authority functions $\mu$ and $\widetilde{\mu}$, each corresponding to a parameter pair $\left(\kappa_{0}, \kappa\right)$ and $\left(\widetilde{\kappa}_{0}, \widetilde{\kappa}\right)$ according to $(9)$, and both of which satisfy the initial condition. Suppose 


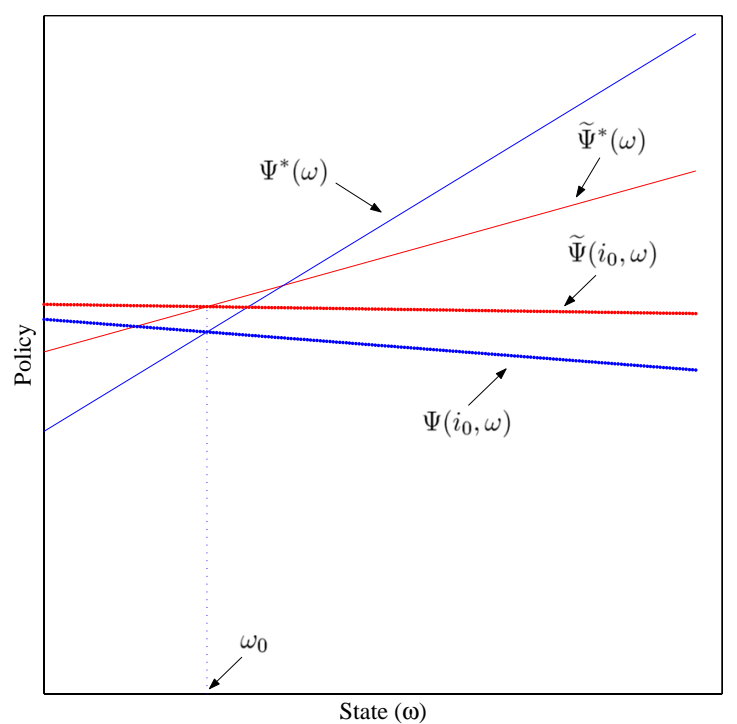

Figure 3: Comparison of Two Political Institutions

$\kappa>\widetilde{\kappa} \geq 0$ (and, consequently, $\left.\kappa_{0}<\widetilde{\kappa}_{0}\right)$. Let $\Psi^{*}$ and $\widetilde{\Psi}$ denote Policy-Endogenous (PE) equilibria under $\mu$ and $\widetilde{\mu}$ respectively, and let $\omega^{*}$ and $\widetilde{\omega}$ denote their corresponding (unique) steady states. Then $\omega^{*}>\widetilde{\omega}$ iff $\omega_{0}<\omega^{*}$. Furthermore, if $\omega_{0}<\omega^{*}$, then there exists a state $\hat{\omega}$ with $\omega_{0}<\hat{\omega}<\omega^{*}$ such that

$$
\begin{aligned}
& \Psi^{*}\left(\omega_{t}\right)<\widetilde{\Psi}\left(\omega_{t}\right) \quad \text { whenever } \omega_{0} \leq \omega_{t}<\hat{\omega} \\
& \Psi^{*}\left(\omega_{t}\right)>\widetilde{\Psi}\left(\omega_{t}\right) \quad \text { whenever } \omega_{t}>\hat{\omega} .
\end{aligned}
$$

whereas if $\omega_{0}>\omega^{*}$, then there exists a state $\hat{\omega}$ with $\omega^{*}<\hat{\omega}<\omega_{0}$ such that

$$
\begin{aligned}
& \Psi^{*}\left(\omega_{t}\right)>\widetilde{\Psi}\left(\omega_{t}\right) \quad \text { whenever } \hat{\omega}<\omega_{t} \leq \omega_{0}, \\
& \Psi^{*}\left(\omega_{t}\right)<\widetilde{\Psi}\left(\omega_{t}\right) \text { whenever } \omega_{t}<\hat{\omega} .
\end{aligned}
$$

Recall that if $\kappa>\widetilde{\kappa}$, then $\mu$ gives a faster structural evolution of political power, while $\widetilde{\mu}$ is more gradual. The intuition is the same as in Part (iii) of Proposition 1. Decision makers respond to a more distorted political institution $\mu$, by choosing more conservative responses. Initially, this Burkean incentive effect outweighs the structural effect from the authority functions. Hence, the more distorted institution $\mu$ initially produces a slower evolution of power and policy than the less distorted one $\widetilde{\mu}$. However, in the long run (including but not restricted to steady states), structural features take over and the more distorted polity produces a faster evolution of leaders and policies. This is illustrated in Figure 3. 


\subsection{Cyclical Faustian Dynamics}

Now consider $\kappa<0$, the case of countervailing distortion. Since $\mu$ slopes downward, increased public investment places power in more fiscally conservative citizen-types.

Proposition 3 Consider any authority function $\mu$ satisfying (9). If $0>\kappa \geq-\frac{1-d}{\delta}-$ $\frac{1+\delta}{1-\delta}\left[(1-d)^{2}+\frac{3+\delta}{1+\delta}(1-d)+\frac{1}{\delta}\right]$, then the following hold.

(i) There exist a decreasing affine Policy-Endogenous (PE) equilibrium policy rule $\Psi^{*}\left(\omega_{t}\right)$ and a nonincreasing, affine hypothetical rule $\Psi\left(i_{0}, \omega_{t}\right)$, each of which are unique in the corresponding class of affine equilibria.

(ii) The PE equilibrium path of states $\left\{\omega_{t}\right\}$ converges to a unique steady state $\omega^{*}$. If $\kappa>$ $-\frac{1-d}{\delta}$, then the convergence is monotonic. However, if $\kappa<-\frac{1-d}{\delta}$, then the economy follows a dampened cycle converging to $\omega^{*}$ such that $\omega_{t}<\omega^{*}$ if and only if $\omega_{t+1}>\omega^{*}$. In either case, if $\omega_{0}<\omega^{*}$, then $\omega_{0}<\omega_{t}$ implies $\Psi^{*}\left(\omega_{t}\right)<\Psi\left(i_{0}, \omega_{t}\right)<\psi\left(\omega_{t}\right)$, whereas if $\omega_{0}>\omega^{*}$, then $\omega_{t}<\omega_{0}$ implies $\Psi^{*}\left(\omega_{t}\right)>\Psi\left(i_{0}, \omega_{t}\right)>\psi\left(\omega_{t}\right)$.

Faustian dynamics can therefore produce political cycles when the authority function is sufficiently distorted downward. The intuition, roughly, is that the evolution of political power counters the evolution of public sector capital. Hence, when fiscally liberal types choose high expenditures, leading to increases in capital stock, this induces a steep drop in the index $i$ that determines the progressivity of the political type. More fiscally conservative types then lower expenditures which, in turn, produce more liberal types, and so on.

Since $\mu$ slopes downward, then whenever the government's capital stock increases, political power moves downward toward more fiscally conservative types. Consequently, the preservation effect induces the initial, liberal, leader to decrease expenditures and hence slow the evolution of political authority as it moves downward. See Figures 4 and 5.

\section{$4 \quad$ A General Monotone Model}

This Section returns to the basic setup in Section 2. For tractability, we restrict attention to increasing authority functions. As before, we compare the PE equilibrium $\Psi^{*}$, the PA equilibrium $\psi$, and the hypothetical rule $\Psi\left(i_{0}, \cdot\right)$.

The main results characterize properties of smooth-limit equilibria, which we define below. A natural decomposition of the Euler equation is established in which the "Burkean" incentives of decision makers to slow the process of political change are isolated and identified. Note 

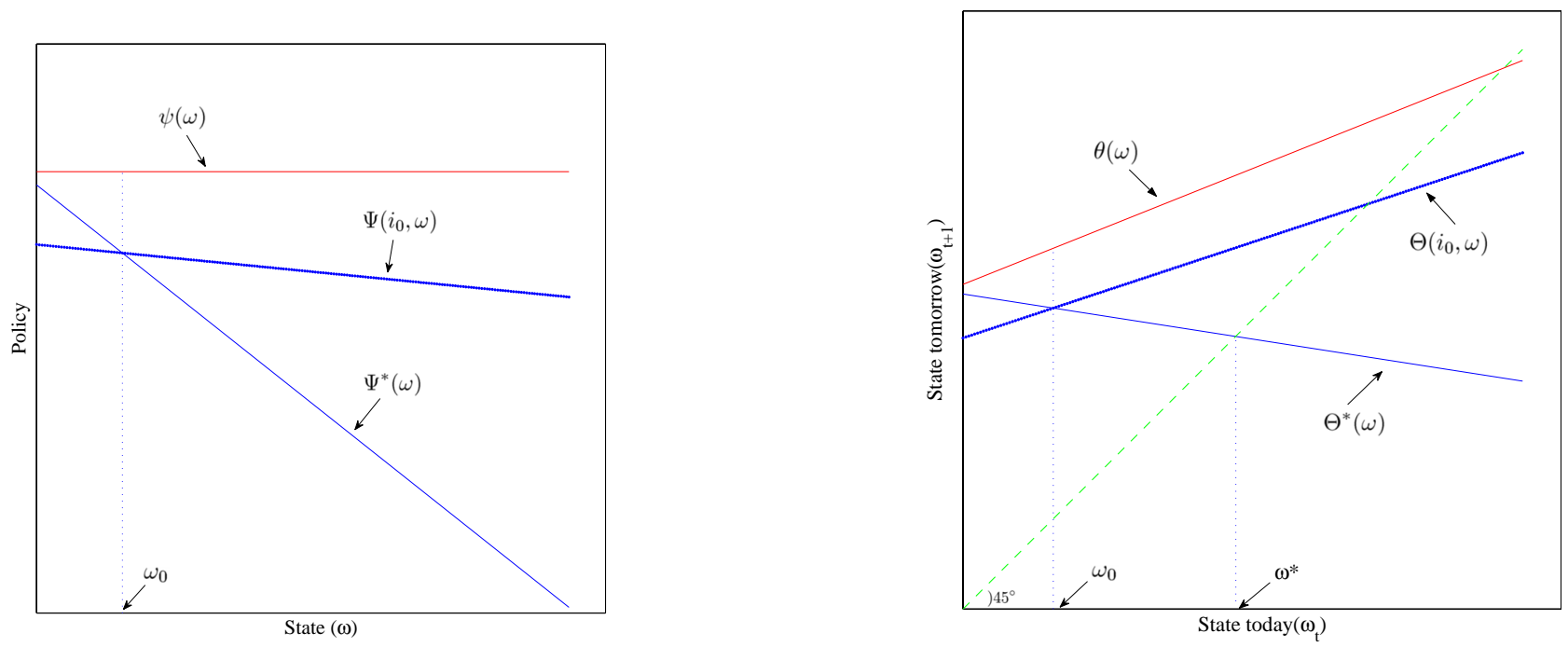

Figure 4: Cyclical Dynamics in the PE and PA Equilibria.

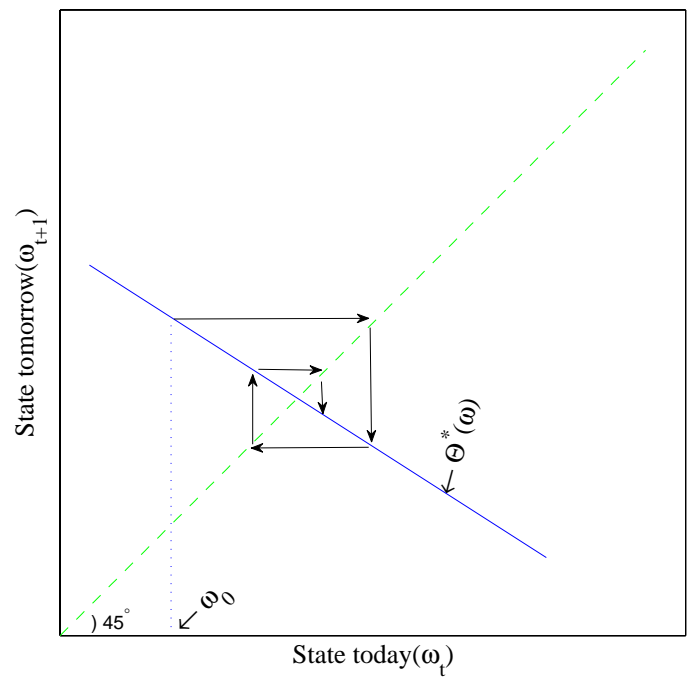

Figure 5: Cycles with Countervailing Bias 
that the public investment model of the previous section is a special case of the general model examined here. All the results of this Section apply there as well. The proofs are in the Appendix.

Smoothness (differentiability) plays a crucial role in our characterization. We use it to examine properties of the Euler equations, roughly following an approach dating back to Basar and Olsder (1982) for dynamic stochastic games. ${ }^{16}$ Results in Judd (2004) suggest that smoothness is a natural selection device when multiple equilibria exist. Formally, a $\mathrm{PE}$ equilibrium $\Psi^{*}$ and PA equilibrium $\psi$ are smooth-limit equilibria if (i) $\Psi^{*}$ and $\psi$ are differentiable in the state; (ii) the resulting policies and $\Psi^{*}\left(\omega_{t}\right)$ and $\psi\left(\omega_{t}\right)$ lie in the interior of the feasible policy space, and (iii) $\Psi^{*}$ and $\psi$ are the limit of smooth, finite horizon PE and PA equilibria, resp. Property (iii) is not necessary in the following characterization of the Euler equation. It is only used later when time-iteration of the value function is the most convenient way of establishing monotonicity in the state.

Issues of equilibrium existence are not explored here. There are, in fact, general existence results for smooth Markov equilibria, but these require stochastic shocks which are absent from our presentation. ${ }^{17}$

\subsection{Distortion-Adjusted Euler Equation}

The applied model in the previous Section introduced the idea of a distortion function. The distortion function represents the wedge in one's long run payoffs arising from the conflict between one's own preferences and that of the decision maker. This conflict distorts the marginal payoff away from its critical value. In the general case, the distortion function is given by:

$$
\Delta\left(i, \omega_{t} ; \Psi^{*}\right)=D_{a_{t}} u\left(i, \omega_{t}, \Psi^{*}\left(\omega_{t}\right)\right)+\delta D_{a_{t}} Q\left(\omega_{t}, \Psi^{*}\left(\omega_{t}\right)\right) \cdot D_{\omega_{t+1}} V\left(i, \omega_{t+1} ; \Psi^{*}\right)
$$

with $\omega_{t+1}=Q\left(\omega_{t}, \Psi^{*}\left(\omega_{t}\right)\right)$. Generally, $\Delta\left(i, \omega_{t} ; \Psi^{*}\right)$ describes the marginal distortion away from the $i$ 's critical value when some possibly different citizen-type makes the policy decision in state $\omega_{t}$. Of course, in the special case where $i=i_{t}=\mu\left(\omega_{t}\right)$, i.e., $i$ is the leader, then there is no distortion. In that case, $\Delta\left(i, \omega_{t} ; \Psi^{*}\right)=0$ describes a first order condition for $i=i_{t}$. Under permanent authority, it also follows that $\Delta\left(i_{0}, \omega_{t} ; \psi\right)=0$ since there is no distortion

\footnotetext{
${ }^{16}$ More recently this approach has been adapted to dynamic macro policy problems by Klein, Krusell, and Rios Rull (2008), Krusell and Smith (2003), Krusell, Kuruscu, and Smith (2002), and Judd (2004), and to dynamic political games by Jack and Lagunoff (2004).

${ }^{17} \mathrm{~A}$ previous draft of this paper had shocks, but we took them out as they added little to the main ideas. Aside from shocks, the remaining assumptions do not appear to violate any of the known existence results as far we are aware. See, for instance, Amir (1996), Curtat (1996), Horst (2005), Lagunoff (2008), and Novak (2007).
} 
when $i_{0}$ holds power forever. The distortion equation (14) can be written as

$$
\delta D_{\omega_{t+1}} V_{i}=\left[D_{a_{t}} Q\right]^{-1} \cdot\left[\Delta\left(i, \omega_{t} ; \Psi^{*}\right)-D_{a_{t}} u_{i}\right]
$$

Next, consider an arbitrary citizen-type $i \in I$ (not necessarily the leader) in the PE equilibrium. His continuation value function in state $\omega_{t+1}$ is

$$
V\left(i, \omega_{t+1} ; \Psi^{*}\right)=u\left(i, \omega_{t+1}, \Psi^{*}\left(\omega_{t+1}\right)\right)+\delta V\left(i, \omega_{t+2} ; \Psi^{*}\right)
$$

with $\omega_{t+2}=Q\left(\omega_{t+1}, \Psi^{*}\left(\omega_{t+1}\right)\right)$. To save on notation, we use the abbreviated notation $u_{i}=$ $u(i, \cdot)$, and $V_{i}=V(i, \cdot)$. Differentiating this value function $V_{i}$ with respect to $\omega_{t+1}$ yields

$$
D_{\omega_{t+1}} V_{i}=D_{\omega_{t+1}} u_{i}+D_{\omega_{t+1}} \Psi^{*} \cdot D_{a_{t+1}} u_{i}+\delta\left[D_{\omega_{t+1}} Q+D_{\omega_{t+1}} \Psi^{*} \cdot D_{a_{t+1}} Q\right] \cdot D_{\omega_{t+2}} V_{i}
$$

Iterating (15) forward one period while holding $i$ fixed, and then substituting it back into (17) yields the expression

$$
D_{\omega_{t+1}} V_{i}=R\left(i_{t}, \omega_{t+1} ; \Psi^{*}\right)+P\left(i_{t}, \omega_{t+1} ; \Psi^{*}\right)
$$

where

$$
\begin{aligned}
& R\left(i_{t}, \omega_{t+1} ; \Psi^{*}\right) \equiv D_{\omega_{t+1}} u_{i_{t}}-D_{\omega_{t+1}} Q \cdot\left[D_{a_{t+1}} Q\right]^{-1} \cdot\left[D_{a_{t+1}} u_{i_{t}}\right] \\
& \text { and } \\
& P\left(i_{t}, \omega_{t+1} ; \Psi^{*}\right) \equiv\left[D_{\omega_{t+1}} Q \cdot\left[D_{a_{t+1}} Q\right]^{-1}+D_{\omega_{t+1}} \Psi^{*}\right] \cdot \Delta\left(i_{t}, \omega_{t+1} ; \Psi^{*}\right)
\end{aligned}
$$

Using these definitions, we substitute (18) into the first order condition $\Delta\left(i_{t}, \omega_{t} ; \Psi^{*}\right)=0$ of the date $t$ leader $i_{t}$, to obtain the Distortion-adjusted Euler equation

$$
D_{a_{t}} u_{i_{t}}+\delta D_{a_{t}} Q \cdot\left[R\left(i_{t}, \omega_{t+1} ; \Psi^{*}\right)+P\left(i_{t}, \omega_{t+1} ; \Psi^{*}\right)\right]=0
$$

where $\omega_{t+1}=Q\left(\omega_{t}, \Psi^{*}\left(\omega_{t}\right)\right)$. The Distortion-adjusted Euler Equation is fundamental to our characterization of the general model. It captures the basic decomposition of motives of any leader when power is policy-endogenous. Each leader weighs the marginal cost $D_{a_{t}} u_{i_{t}}$ against two types of marginal effects.

Starting first with the second effect, the term $P\left(i_{t}, \omega_{t+1} ; \Psi^{*}\right)$, is closely identified with the Faustian trade off. Intuitively, it describes the marginal loss in $i_{t}$ 's payoff which is brought about when the policy induces a sequence of different, and clearly less desirable, political leaders in the future. These future leaders choose policies that distort one's dynamic marginal payoff away from its critical value. These distortions begin with the decision $a_{t+1}$ made by 
$i_{t+1}$ whose preferences may differ from $i_{t}$. We refer to $P\left(i_{t}, \omega_{t+1} ; \Psi^{*}\right)$ as the Preservation Effect because, as we later show, it induces Burkean conservatism by decision makers. In the public investment model, the preservation effect is given by $(K+1-d) \Delta\left(i_{t}, \omega_{t+1} ; \Psi^{*}\right)$ which is negative, a fact that we later show is robust. Note that the Preservation Effect vanishes in the PA equilibrium. That is, $P\left(i_{t}, \omega_{t+1} ; \psi\right)=0$, due to the Envelope Theorem.

The Preservation Effect may be partly offset by a standard dynamic programming term in the form of $R\left(i_{t}, \omega_{t+1} ; \Psi^{*}\right)$ defined in (18.a). Qualitatively, the term $R$ arises in the typical Euler equations. Roughly, it describes the marginal effect of a change in next period's state $\omega_{t+1}$ on next period's payoffs after adjusting policy so that the subsequent state $\omega_{t+2}$ remains at the level chosen by $i_{t+1}$ in equilibrium (since changes in $\omega_{t+2}$ come from next period's leader $i_{t+1}$, hence are part of the Preservation Effect).

The first term in Equation (18.a) describes the direct gain in $i_{t}$ 's payoff next period from a change in $\omega_{t+1}$. The second term describes the indirect gain from reduced cost of the policy in $t+1$. Specifically, a unit increase in $\omega_{t+1}$ lowers the required policy $a_{t+1}$ by $D_{\omega_{t+1}} Q$. $\left[D_{a_{t+1}} Q\right]^{-1}$ in order to achieve the state $\omega_{t+2}$ that $i_{t}$ anticipates will be induced by $i_{t+1}$ 's policy in equilibrium. ${ }^{18}$ In turn, this leads to a change in payoff equaling this second term. While the functional form $R$ is standard, its magnitude differs across PA and PE regimes. We refer to the difference $R\left(i, \omega_{t+1} ; \Psi^{*}\right)-R\left(i, \omega_{t+1} ; \psi\right)$ as the Reformation Effect because it reflects the net incentive distortion due to the productivity differences of a current policy choice in $\mathrm{PE}$ relative to PA. A higher level of future investment under $\Psi^{*}$ may increase one's incentive to invest more today. From Equation (13), the reformation effect in the public investment model, for instance, is calculated to be $(1-d)\left(\Psi^{*}\left(\omega_{t+1}\right)-\psi\left(\omega_{t+1}\right)\right)$. Since $\psi$ is stationary in that model, the reformation effect is increasing in the state. Using Proposition 1 , the reformation effect is negative at states below a cutoff $\hat{\omega}$, and positive at states above it.

Because the Preservation Effect vanishes under permanent authority, the Euler equation in the PA equilibrium is given by

$$
D_{a_{t}} u_{i_{0}}+\delta D_{a_{t}} Q \cdot R\left(i_{0}, \omega_{t+1} ; \psi\right)=0
$$

where $\omega_{t+1}=Q\left(\omega_{t}, \psi\left(\omega_{t}\right)\right)$. Consequently, the net effect on continuation payoffs of policyendogenous power, relative to permanent authority, is given by

$$
\overbrace{R\left(i, \omega_{t+1} ; \Psi^{*}\right)-R\left(i, \omega_{t+1} ; \psi\right)}^{\text {Reformation Effect }}+\overbrace{P\left(i, \omega_{t+1} ; \Psi^{*}\right)}^{\text {Preservation Effect }}
$$

With the aid of a supermodularity assumption defined below, we use these terms to identify features of the PE equilibrium.

\footnotetext{
${ }^{18}$ Note that both terms in the expression for $R$ affect only payoffs in $t+1$. This is because the effect on periods $t+2$ onward depends on the marginal variation of the policy rules that come from variations in the identity of the decision makers. These variations appear in the Preservation Effect and would be fully "enveloped out" in the standard, single agent dynamic programming problems.
} 


\subsection{Supermodularity and Monotonicity}

A central feature of the public investment model is monotonicity. In one case, political power shifts from lower to higher marginal valuation types, and this occurs when equilibrium policy rules are increasing in the state. In the second case, the paths exhibit cycles, with dampened oscillations between high and low valuation types. This occurs when equilibrium policy rules are decreasing in the state.

The monotonicity of the policy rule in these cases owes not so much to the specific functional forms, but (as we later show) rather to the fact that these functional forms are supermodular. This is no accident. Supermodularity is the more general version of a collection of commonly used assumptions (e.g., increasing differences, strategic complements, etc.), that are generally used to establish monotonicity and/or well defined monotone comparative statics of endogenous decision rules. Here it is central in our efforts to characterize Faustian tradeoffs. In smooth (differentiable) models, the definition is straightforward. A smooth function $f: \mathbb{R}^{m} \rightarrow \mathbb{R}$ is supermodular (spm) iff $D_{x_{j}} D_{x_{k}} f \geq 0$ for all $j, k=1, \ldots, m$, and $f$ is strictly $s p m$ if the inequality is strict.

First, define $a_{t}=L\left(\omega_{t}, \omega_{t+1}\right)$ implicitly from the transition equation $Q\left(\omega_{t}, L\left(\omega_{t}, \omega_{t+1}\right)\right)=$ $\omega_{t+1}$. The function $L\left(\omega_{t}, \omega_{t+1}\right)$ is interpreted as the policy cost of generating tomorrow's state $\omega_{t+1}$ given current state $\omega_{t}$.

(A1). Supermodularity (spm). The composite flow payoff defined by $\tilde{u}\left(i, \omega_{t}, \omega_{t+1}\right) \equiv u\left(i, \omega_{t}, L\left(\omega_{t}, \omega_{t+1}\right)\right)$ is supermodular in $\left(i, \omega_{t}, \omega_{t+1}\right)$ and strictly supermodular in $\left(i, \omega_{t}\right)$.

The composite flow payoff captures both the static payoff effect of a change in policy and its future consequence through $L$. Hence, by placing joint restrictions on $u$ and $Q$ through the composite payoff $\tilde{u}$, Assumption (A1) is weaker than separate spm assumptions on $u$ and $Q$. Still, it is not unrestrictive. As with all spm assumptions, (A1) applies only to environments with sufficiently strong complementarities between endogenous variables and exogenous parameters and between different sets of endogenous variables. It holds in most models of capital accumulation via taxation by a government since a government's current investment typically increases the productivity of its future investment. In the public investment model, for instance, $(\mathrm{A} 1)$ is easily verified since $\tilde{u}=f(i) \omega_{t}-1 / 2\left(\omega_{t+1}-(1-d) \omega_{t}\right)^{2}$.

On the other hand, spm often does not hold in situations where there are free rider problems as in, for instance, cases where public good provision is decentralized and voluntary. In such cases, an individual's marginal incentive to contribute diminishes the larger is the sum of others' contributions. The present model does not have this problem since public provision is centralized through a pivotal voting mechanism of one kind or another. 
Theorem 1 Suppose that (A1) holds. Then in any smooth-limit Policy-Endogenous equilibrium $\Psi^{*}$, citizen-type $i$ 's dynamic payoff, $u\left(i, \omega_{t}, a_{t}\right)+\delta V\left(i, Q\left(\omega_{t}, a_{t}\right) ; \Psi^{*}\right)$, is supermodular in $i$ and $a_{t}$.

Application of the Theorem, combined with standard results in voting theory (for instance, Gans and Smart (1996)) show that the Median Voter Theorem applies. ${ }^{19}$ Of course, for a given $\mu$ this median may be weighted as in Equation (8). Theorem 1 implies then that there exists a (possibly weighted) state-dependent voting rule such that the rule admits a pivotal voter $\mu\left(\omega_{t}\right)$ in state $\omega_{t}$.

A secondary consequence of spm is that it allows for a straightforward comparison of $\mathrm{PE}$ to the PA equilibrium based on the reformation effect alone.

Theorem 2 Suppose Assumption (A1) holds. For each citizen-type $i$ and each state $\omega_{t}$, $\Psi^{*}\left(\omega_{t}\right) \geq \psi\left(\omega_{t}\right)$ iff $R\left(i, \omega_{t} ; \Psi^{*}\right) \geq R\left(i, \omega_{t} ; \psi\right)$.

Under (A1), a well ordered evolution of political authority exists in PE equilibria.

Theorem 3 Suppose (A1) holds. Let $\Psi^{*}$ be a smooth-limit Policy-Endogenous (PE) equilibrium and let $\Theta^{*}\left(\omega_{t}\right) \equiv Q\left(\omega_{t}, \Psi^{*}\left(\omega_{t}\right)\right)$ be the associated PE equilibrium transition rule. Then, $\Theta^{*}$ is increasing, and for any state $\omega_{t} \geq \omega_{0}, \Psi^{*}\left(\omega_{t}\right) \geq \Psi\left(i_{0}, \omega_{t}\right)$ with strict inequality if $\omega_{t}>\omega_{0}$.

The Theorem shows that the PE equilibrium transition rule is monotone in states, and the hypothetical PE rule is more conservative (in the natural order on policies) in every state than in the PE equilibrium. By itself, Theorem 3 does not say much about Faustian dynamics. However, under a simple initial condition, the following Corollary asserts that Faustian dynamics are monotone.

Corollary Suppose that, in addition to the assumptions of Theorem $3, \Theta^{*}\left(\omega_{0}\right)>\omega_{0}$. Then the Policy-Endogenous equilibrium paths of states $\left\{\omega_{t}\right\}$ and leaders $\left\{i_{t}\right\}$ are increasing: $\omega_{t+1}>\omega_{t}$ and $i_{t+1}>i_{t}$.

The Corollary asserts that the PE equilibrium path of states and decision-making types is increasing provided it starts off that way. Hence, current leaders knowingly lose power to more progressive decision types, and this evolution continues until either a steady state is reached, or until the largest (most progressive) type acquires power.

\footnotetext{
${ }^{19}$ Assumption A1 implies that the payoff satisfies single crossing in $i$ and $a_{t}$. Hence, the application of Gans' and Smart's result applies. See also Roberts $(1998,1999)$ for another application of spm to a dynamic political economy model of club admissions.
} 
Finally, spm is used to show that one critical feature of the public investment model holds quite broadly. So-called "Burkean" incentives for conservative decision making are embodied in the Preservation Effect.

Theorem 4 Suppose (A1) holds. Let $\Psi^{*}$ be a smooth-limit PE equilibrium. For each state $\omega_{t+1}, P\left(i, \omega_{t+1} ; \Psi^{*}\right)$ is increasing in $i$, and

$$
P\left(i, \omega_{t+1} ; \Psi^{*}\right)<0 \quad \text { if and only if } i<\mu\left(\omega_{t+1}\right)
$$

In particular, the result implies that political leaders act in such a way as to offset, at least partially, the loss of political authority resulting from their policy decisions. Hence if the Faustian dynamics move toward more progressive leaders, then the Preservation Effect pushes the current leader toward a more conservative policy. If the evolution is toward less progressive leaders, then the current leader acts more progressively. Combining Theorem 4 with the initial condition that $\Theta^{*}\left(\omega_{0}\right)>\omega_{0}$ implies that the Preservation Effect is negative along the PE equilibrium path: $P\left(\mu\left(\omega_{t}\right), \omega_{t+1} ; \Psi^{*}\right)<0$.

\subsection{Steady States}

By definition, the Preservation Effect vanishes in any steady state $\omega^{*}=\Theta^{*}\left(\omega^{*}\right) \equiv Q\left(\omega^{*}, \Psi^{*}\left(\omega^{*}\right)\right)$ of a PE equilibrium. The identity of the leader clearly does not change once $\omega^{*}$ is reached. Consequently, the distortion adjusted Euler equation for the steady state leader $i^{*}=\mu\left(\omega^{*}\right)$ satisfies

$$
D_{a_{t}} u\left(\mu\left(\omega^{*}\right), \omega^{*}, \Psi\left(\omega^{*}\right)\right)+\delta D_{a_{t}} Q \cdot R\left(\mu\left(\omega^{*}\right), \omega^{*} ; \Psi^{*}\right)=0
$$

From the definition of $R\left(\mu\left(\omega^{*}\right), \omega^{*} ; \Psi^{*}\right)$ in (18.a), observe that $\Psi^{*}$ enters $R$ only through the value of steady state policy $a^{*}=\Psi\left(\omega^{*}\right)$. Equation (23) therefore provides a joint restriction on $\omega^{*}$ and $a^{*}$. Combined with the transition equation $\omega^{*}=Q\left(\omega^{*}, a^{*}\right)$, Equation (23) gives a condition on the determination of $\omega^{*}$ purely in terms of economic primitives. This fact can be seen more clearly in terms of the composite payoff $\tilde{u}\left(i, \omega_{t}, \omega_{t+1}\right)$ defined in Assumption (A1). By definition, $\tilde{u}\left(i, \omega_{t}, Q\left(\omega_{t}, a_{t}\right)\right)=u\left(i, \omega_{t}, a_{t}\right)$ holds as an identity. By taking partial derivatives of this identity with respect to $\omega_{t}$ and $a_{t}$, it follows that $D_{a_{t}} u\left(i, \omega_{t}, a_{t}\right)=D_{\omega_{t+1}} \tilde{u}\left(i, \omega_{t}, \omega_{t+1}\right) D_{a_{t}} Q\left(\omega_{t}, a_{t}\right)$ and $R\left(i, \omega_{t+1} ; \Psi^{*}\right)=D_{\omega_{t+1}} \tilde{u}\left(i, \omega_{t+1}, \omega_{t+2}\right)$. Evaluating these at the steady state values, Equation (23) reduces to

$$
D_{\omega_{t+1}} \tilde{u}\left(\mu\left(\omega^{*}\right), \omega^{*}, \omega^{*}\right)+\delta D_{\omega_{t+1}} \tilde{u}\left(\mu\left(\omega^{*}\right), \omega^{*}, \omega^{*}\right)=0
$$

The steady state equation (24) expresses a simple marginal tradeoff in the steady state. In the public investment model, this tradeoff was between present and future public sector capital. Similarly, $\omega^{\circ}=Q\left(\omega^{\circ}, \psi\left(\omega^{\circ}\right)\right)$ is a steady state in the PA equilibrium and the steady state equation is given by

$$
D_{\omega_{t+1}} \tilde{u}\left(i_{0}, \omega^{\circ}, \omega^{\circ}\right)+\delta D_{\omega_{t+1}} \tilde{u}\left(i_{0}, \omega^{\circ}, \omega^{\circ}\right)=0
$$


Theorem 5 Suppose (A1) holds, and let $\Psi^{*}$ and $\psi$ be smooth-limit PE and PA equilibria, respectively. Then

(i) $\omega^{*}$ is a steady state of $\Psi^{*}$ iff (24) is satisfied, and $\omega^{\circ}$ is a steady state of $\psi$ iff (25) is satisfied.

(ii) The PE steady state $\omega^{*}$ is unique if

$$
D_{\omega_{t+1}} \tilde{u}(\mu(\omega), \omega, \omega)+\delta D_{\omega_{t+1}} \tilde{u}(\mu(\omega), \omega, \omega) \text { is decreasing in the state } \omega .
$$

and the PA steady state $\omega^{\circ}$ is unique if

$$
D_{\omega_{t+1}} \tilde{u}\left(i_{0}, \omega, \omega\right)+\delta D_{\omega_{t+1}} \tilde{u}\left(i_{0}, \omega, \omega\right) \text { is decreasing in the state } \omega .
$$

(iii) Suppose that (27) holds for each $i$. Then $\omega^{*}>\omega^{\circ}$ iff $\omega^{*}>\omega_{0}$.

Properties (i)-(iii) are all satisfied in the stylized model. Hence, the conclusions of the Theorem apply, indicating a degree of robustness of the steady state properties of that model.

Property (iii) is perhaps the most significant of the three. It relates the long-run in the $\mathrm{PE}$ equilibrium to the long run under permanent authority. It suggests that in the long run at least, progressive change in policy is not hindered by political expediency.

\section{Related Literature and Discussion}

The dynamic link between policy and power shows up in a small but growing number of papers. For purposes of relating these to the present paper, we found it most useful to separate them into two groups. One consists of models of one or two-period lived agents; the other consists of models with longer lived agents. As it turns out, there is an important difference which our general model allows us to identify.

Milesi-Ferretti and Spolaore (1994) and Besley and Coate (1998) are early contributions to the first category of papers. They posit interesting two-period models in which a policymaker's first period decision influences voter choices in the second. A "political failure", as Besley and Coate describe it, occurs when policy-endogenous loss of political control in the future lead to inefficient policy choices in the present.

Similarly, Bourguignon and Verdier (2000) explore a policy-endogenous mechanism that works through education and its effect on political participation. Policies that change the level and distribution of education also change political participation across different groups. 
Dolmas and Huffman (2004)'s policy-endogenous mechanism works through immigration. Immigration policy is determined by majority vote, and immigration changes the identity of the median voter in the subsequent period. Campante (2007) examines a related mechanism that works through campaign contributions. In this case, policies that change income distribution alter the composition of contributions that, in turn, determine who is elected.

Hassler, et. al. (2003) investigate the evolution of the welfare state in a parametric overlapping-generations model. A majority vote determines the level of transfers to unsuccessful agents. Because the population sizes of different types are endogenously determined by individual investment decisions, their model can generate a shift of political power even with majority voting. ${ }^{20}$

These studies highlight the broad array of mechanisms through which Faustian trade offs occur. We view the present model as complementary to these in that it suggests that equilibria in these frameworks have elements in common. Our findings also suggest some possible missing ingredients. Because agents in these models live (at most) two periods, the Faustian trade off is essentially one-shot. This means that a date $t$ agent need not worry about the distortionary effect his policy has on distribution of power beyond $t+1$. In other words, these models have a reformation effect but no preservation effect. This is significant because the two effects often work in opposite directions. Our results suggest that the time paths of models with and without the preservation effect would be quite different.

Recent papers by Azzimonti (2005) and Ortega (2005) do have preservation effects in models with infinitely lived agents. Like Dolmas' and Huffman's model, Ortega (2005) studies a natural policy-endogenous mechanism in the form of immigration. Ceteris paribus, current residents want to admit immigrants with complementary skills. On the other hand such immigrants are future voters who will vote to admit future immigrants whose skills are substitutes to those of the current residents. Azzimonti (2005) posits an interesting model of dynamic inefficiency in government. An inefficiency arises because the dominant faction loses power to the other due to political shocks. She endogenizes the switching likelihoods between the two factions by introducing probabilistic voting. When the shocks to voters' ideological preferences for one group are asymmetric, then increases in public spending change voters' relative preferences between the groups, and so the identity of the pivotal voter changes as well.

Both these papers have something akin to both reformation and preservation effects. Azzimonti, in fact, emphasizes a decomposition of motives in an Euler equation related to the one in our stylized model. ${ }^{21}$ However, the focus of these models is elsewhere, and both models' assumption of two political types/factions makes the Burkean conservatism of their decision

\footnotetext{
${ }^{20}$ Although, in their model, endogenous change in political power occurs mainly through private sector investment decisions rather than directly from current policies. A related model and policy-endogenous mechanism is studied in Hassler, et. al. (2005).

${ }^{21}$ Interestingly, her decomposition also includes exogenous inconsistency arising due to shocks rather than due to non-stationarity.
} 
makers difficult to identify. The present study therefore recasts these papers in a new light, allowing a clear view of subtle attributes that two seemingly different models have in common.

Clearly, one would not want to argue that all policy choices involve Faustian trade offs. In fact, a parallel literature has arisen that "un-couples" policy from political power by allowing the voters an explicit choice over political institutions. For instance, Acemoglu and Robinson (2000, 2001, 2006), Cervelatti, et. al. (2006), Jack and Lagunoff (2006a,b), Persson and Tabellini (2007) and Lagunoff $(2008,2009)$ all examine models of explicit institutional (de jure) choices by current elites or majorities as a way of reversing or mitigating the deleterious effects of current policy on one's future political fortunes. Similarly, Roberts $(1998,1999)$ and Barbera, Maschler, and Shalev (BMS) (2001) un-couple the policy-political choice by placing attributes of a future pivotal or marginal voter directly in the preferences of the current voter. In this sense, the policy itself is the composition of political power.

These "un-coupling" models make sense when current elites have the flexibility to isolate or reverse the consequences of their policy choices. Our mechanism is appropriate when this flexibility is lacking.

This contrast is apparent in a recent model of Acemoglu and Robinson (2008). Building on an earlier framework laid out in Acemoglu, Johnson, and Robinson (2005), they model the policy decisions of an elite that explicitly preserve de facto political power when exogenous, de jure changes in the political system moves the country toward democracy. They identify "captured democracies" as those in which an elite's investments succeed in preserving power. The key difference between their model and ours is that in our model, policies generate political change, while in theirs, policies are used by elites to undo (exogenous) political change. Acemoglu and Robinson look to 20th century Latin America for numerous instances of captured democracies. On the other hand, the collapse of the Soviet Union, and the role of Glasnost in facilitating the change in power, suggests a Faustian trade off at work. A decision maker (Gorbachev) turned "Burkean" as he attempted moderate reforms that eventually lead to a, perhaps unavoidable, loss of his own power.

Finally, we return to the policy decision of Lyndon Johnson which was initially presented as an example of Faustian trade offs. It was clearly part of a broader trend toward more progressive civil rights laws. The effects of Faustian trade offs on incentives were apparently widespread in this case. Rodriguez and Weingast (2006) describe, for instance, how the 1964 Civil Rights Act was watered down to minimize the political impact for Northern legislators. ${ }^{22}$

\footnotetext{
${ }^{22}$ As Rodriguez and Weingast describe it, concessions in the Act were made to garner support from Northern Republicans. However, many Democrats as well as Republicans feared political fallout from Northern whites at the time. See, for instance, Stewart (1997).
} 


\section{Concluding Remarks}

This paper analyzes the dynamics of a "Faustian trade-off" between policy and political power. We characterize this trade-off in terms of a distortion-adjusted Euler equation that illustrates the two main motives of a political actor: the desire for gradualism on the one hand, and the need for policy reformation on the other. We demonstrate how the tradeoff works in both a stylized model of public investment, and in a general monotone model.

The parametric results focus on the interaction between political bias and distributional change for creating a Faustian trade-off. When the resulting distortion is reinforcing it gives rise to equilibria with monotone dynamics. By contrast, under a countervailing distortion, one can have both monotone and cyclical dynamics, however only cyclical dynamics can arise if the distortion is strong enough.

In either case, Faustian trade offs turn political leaders into "Burkean conservatives" who moderate their decisions in order to influence the future political evolution. This Burkean influence on individual incentives is a key consequence of the Faustian trade off. However, the Burkean influence must be weighed against the the dynamic change in political types when assessing the overall effect on the equilibrium path. In the short-run the Burkean influence dominates when the PE equilibrium is compared with the PA model. In the long-run, however, the "type effect" dominates. This indicates that there are critical features in the transition dynamics of the Faustian model that would not be evident by focusing only on steady state properties.

A few modeling choices warrant further discussion. First, decision makers are assumed to be exclusively policy-driven. Their desire for power is therefore purely instrumental. (This is in keeping with the original depiction of Faust as a well-intentioned character.) There are likely many historical examples of leaders who desire power for its own sake. It would not be difficult to incorporate "power-hungry" leaders into the model, however, this extension would be, in our view, rather prosaic.

Second, we omit stochastic shocks. Decision makers in the model choose not so much whether to lose power, but by how much and to whom. Consequently, we omit the case where leaders are uncertain about the political ramifications of their policies. As it turns out shocks do not fundamentally change the nature of the Faustian trade-off. They do introduce, however, risk aversion into the motives of the leader, and for this reason, would be a useful addition to future work.

On a related point, note that the model looks only at endogenous changes in political power. Of course, there may also be incentive effects due to exogenous political change. These exogenous sources of change may be due to shocks, but they may also be built in to the authority rule. Exogenous sources of political change would move the analysis closer to 
traditional models of dynamically inconsistent policy choice - for instance hyperbolic $\beta-\delta$ policy models ${ }^{23}$ as well the famous fiscal policy models of Persson and Svensson (1989) and Alesina and Tabellini (1990). In these models a marginal effect somewhat similar to the preservation effect arises due to the conflict between current and future decision makers as calendar time changes the identity of the decision maker. Azzimonti's (2005) parametric model shows this explicitly.

Third, the stylized (parametric) model generates some fairly specific results on public investment, growth, and political change. Because the investment is assumed to be financed by lump sum taxation, no distortions arise other than that induced by the Faustian trade off. This is by design, given the focus of the paper. However, recent papers of Battaglini and Coate $(2007,2008)$ have made in-roads into our understanding of the dynamic political economy of distortionary taxation. At this stage there is still much work to do, and in light of the present results, explorations on the interaction between Faustian and tax distortions seem well worth the effort.

Finally, throughout the analysis, we keep the political institution exogenous in the analysis. We focus only on the de facto evolution of the political power within a stable (de jure) political institution. This allows us to examine the consequences of exogenous changes in political institutions. By construction, the framework does not answer the question of why a certain political institution is chosen and what determines the evolution of the de jure political institution. Future work could investigate the interaction of the policy-endogenous political power and policy-endogenous political institutions.

\section{$7 \quad$ Appendix}

Proof of Parts (i) in Propositions 1 and 2. For brevity, we combine Parts (i) of Propositions 1 and 2, since the argument does not depend per se on whether $\kappa>0$ or $\kappa<0$.

We first conjecture a solution $\Psi^{*}$ of the affine form $\Psi^{*}(\omega)=(d-K) \omega^{*}+K \omega$ where $K$ is a constant (in $\omega$ ), though we later show how it varies with $\kappa . \omega^{*}$ is the steady state which depends on $\kappa$ and $\kappa_{0}$. The conjecture is used to characterize both $\Psi^{*}$ and $\Psi$, the hypothetical rule. We establish a solution for coefficients $\left(K, \omega^{*}\right)$ and establish uniqueness. We then characterize the case with $\kappa=0$, and show that $K=0$ there. This case gives us the PA equilibrium $\psi$.

Step $1^{\circ}$. Verifying the Functional Forms. Using the affine form as our "guess" the flow utility

\footnotetext{
${ }^{23}$ See Laibson (1997), Harris and Laibson (2001), Krusell, Kuruscu and Smith (2002), Krusell and Smith (2003), Amador (2003), Judd (2004).
} 
is

$$
\begin{aligned}
u(i, \omega, a) & =f(i) \omega-\frac{1}{2}\left((d-K) \omega^{*}+K \omega\right)^{2} \\
& =f(i) \omega^{*}-\frac{1}{2} d^{2} \omega^{* 2}+\left(f(i)-d \omega^{*} K\right)\left(\omega-\omega^{*}\right)-\frac{1}{2} K^{2}\left(\omega-\omega^{*}\right)^{2}
\end{aligned}
$$

For the purpose of solving for the equilibrium, we can drop the constant term. The continuation utility for an arbitrary $i$ is

$$
\begin{aligned}
V\left(i, \omega_{t} ; \Psi^{*}\right) & =\sum_{s=0}^{\infty} \delta^{s} u\left(i, \omega_{t+s}, \Psi^{*}\left(\omega_{t+s}\right)\right) \\
& =\sum_{s=0}^{\infty} \delta^{s}\left[\left(f(i)-d \omega^{*} K\right)\left(\omega_{t+s}-\omega^{*}\right)-\frac{1}{2} K^{2}\left(\omega_{t+s}-\omega^{*}\right)^{2}\right] \\
& =\frac{f(i)-d \omega^{*} K}{1-\delta(K+1-d)}\left(\omega_{t}-\omega^{*}\right)-\frac{1}{2} \frac{K^{2}}{1-\delta(K+1-d)^{2}}\left(\omega_{t}-\omega^{*}\right)^{2}
\end{aligned}
$$

where the last line follows from the fact that $\omega_{t+s}-\omega^{*}=(K+1-d)^{s}\left(\omega_{t}-\omega^{*}\right)$. The last equality above requires convergence of the infinite sum which, in turn, requires $K+1-d<\frac{1}{\delta}$ and $(K+1-d)^{2}<\frac{1}{\delta}$ which combines to $K+1-d<\frac{1}{\sqrt{\delta}}$. The hypothetical problem confronting an arbitrary citizen-type $i$ is

$$
\max _{a_{t}}\left\{u\left(i, \omega_{t}, a_{t}\right)+\delta V\left(i,(1-d) \omega_{t}+a_{t} ; \Psi^{*}\right)\right\}
$$

which, when evaluated at the parametric assumptions produces the first-order condition

$$
-a_{t}+\delta\left[\frac{f(i)-d \omega^{*} K}{1-\delta(K+1-d)}-\frac{K^{2}}{1-\delta(K+1-d)^{2}}\left((1-d) \omega_{t}+a_{t}-\omega^{*}\right)\right]=0
$$

The first-order condition (28) determines the hypothetical PE policy rule:

$$
\begin{aligned}
\Psi\left(i, \omega_{t}\right)= & \frac{1}{1}+\frac{\delta K^{2}}{1-\delta(K+1-d)^{2}}\left[\delta \frac{f(i)}{1-\delta(K+1-d)}\right. \\
& \left.+\delta \omega^{*} K\left(\frac{K}{1-\delta(K+1-d)^{2}}-\frac{d}{1-\delta(K+1-d)}\right)-\frac{\delta K^{2}(1-d)}{1-\delta(K+1-d)^{2}} \omega_{t}\right]
\end{aligned}
$$

We return to the hypothetical equilibrium later. To determine the PE equilibrium, substitute $f(\mu(\omega))=\kappa_{0}+\kappa \omega$ in $(29)$ to derive

$$
\begin{aligned}
\Psi^{*}\left(\omega_{t}\right)= & \frac{1}{1+\frac{\delta K^{2}}{1-\delta(K+1-d)^{2}}}\left[\frac{\delta \kappa_{0}}{1-\delta(K+1-d)}+\delta \omega^{*} K\left(\frac{K}{1-\delta(K+1-d)^{2}}-\frac{d}{1-\delta(K+1-d)}\right)\right. \\
& \left.+\left(\frac{\delta \kappa}{1-\delta(K+1-d)}-\frac{\delta K^{2}(1-d)}{1-\delta(K+1-d)^{2}}\right) \omega_{t}\right]
\end{aligned}
$$


Hence, in order for $\Psi^{*}\left(\omega_{t}\right)=(d-K) \omega^{*}+K \omega_{t}$ to be a PE equilibrium, we must have

$$
\begin{aligned}
K & =\frac{\frac{\delta \kappa}{1-\delta(K+1-d)}-\frac{\delta K^{2}(1-d)}{1-\delta(K+1-d)^{2}}}{1+\frac{\delta K^{2}}{1-\delta(K+1-d)^{2}}}, \text { and } \\
(d-K) \omega^{*} & =\frac{\frac{\delta \kappa_{0}}{1-\delta(K+1-d)}+\delta \omega^{*} K\left(\frac{K}{1-\delta(K+1-d)^{2}}-\frac{d}{1-\delta(K+1-d)}\right)}{1+\frac{\delta K^{2}}{1-\delta(K+1-d)^{2}}} .
\end{aligned}
$$

We therefore have two equations, and two unknowns, $K$ and $\omega^{*}$. In what follows, we verify that there exists a unique pair $\left(K, \omega^{*}\right)$ that satisfy (31) and (32).

Step $2^{\circ}$. Existence and uniqueness of the pair $\left(K, \omega^{*}\right)$. The equation for $K$ in (31) can be expressed as

$$
K+\frac{\delta K^{2}(K+1-d)}{1-\delta(K+1-d)^{2}}-\frac{\delta \kappa}{1-\delta(K+1-d)}=0 .
$$

Define $\widehat{K}=K+1-d$. Multiply both sides of the equation (33) by

$$
\left(1-\delta(K+1-d)^{2}\right)(1-\delta(K+1-d))
$$

and after some messy algebra, the equation (33) becomes

$$
\begin{aligned}
F(\widehat{K}) \equiv \delta & (1-d) \widehat{K}^{3}+\left(\kappa \delta-(2-d)-\delta(1-d)^{2}\right) \widehat{K}^{2} \\
& +\left(\frac{1}{\delta}+(1-d)+(1-d)^{2}\right) \widehat{K}-\left(\kappa+\frac{1}{\delta}(1-d)\right)=0 .
\end{aligned}
$$

Observe that the function $F$ is of the form $F(\widehat{K})=a_{0}(\kappa)+a_{1} \widehat{K}+a_{2}(\kappa) \widehat{K}^{2}+a_{3} \widehat{K}^{3}$ (given the expression above, it should be clear that $a_{0}$ and $a_{2}$ vary with $\kappa$ whereas $a_{1}$ and $a_{3}$ do not). We then have

$$
\begin{aligned}
F(1-d) & =-\kappa\left(1-\delta(1-d)^{2}\right), \\
F(1) & =(1-\delta)\left(d\left(\frac{1}{\delta}-1+d\right)-\kappa\right) \\
F(-1) & =\left(\kappa+\frac{1-d}{\delta}\right)(\delta-1)-(1+\delta)\left[(1-d)^{2}+\frac{3+\delta}{1+\delta}(1-d)+\frac{1}{\delta}\right] \\
F(0) & =-\left(\kappa+\frac{1}{\delta}(1-d)\right)
\end{aligned}
$$

Suppose first that $0<\kappa<d\left(\frac{1}{\delta}-1+d\right)$ as required in Proposition 1. Then $F(1-d)<0$ and $F(1)>0$. Then from the Intermediate Value Theorem, there exists a $\widehat{K}^{*}$ such that $1-d<\widehat{K}^{*}<1$ (or equivalently $0<K^{*}<d$ ) and $F\left(\widehat{K}^{*}\right)=0$. 
Suppose next that $0>\kappa>-\frac{1-d}{\delta}-\frac{1+\delta}{1-\delta}\left[(1-d)^{2}+\frac{3+\delta}{1+\delta}(1-d)+\frac{1}{\delta}\right]$ as required in Proposition 2. Then $F(-1)<0$ and $F(1-d)>0$. Once again, we apply the Intermediate Value Theorem to show that there exists a $-1<\widehat{K}^{*}<(1-d)$ (or equivalently $-(2-d)<K^{*}<0$ ) such that $F\left(\widehat{K}^{*}\right)=0$.

To show uniqueness of the solution $\widehat{K}^{*}$ in either the case of $\kappa>0$ or $\kappa<0$, it suffices to show that $F(\widehat{K})$ is concave, i.e., $F^{\prime \prime}(\widehat{K})=2\left(a_{2}(\kappa)+3 a_{3} \widehat{K}\right)<0$ for $-1 \leq \widehat{K} \leq 1$. Towards this goal, it suffices to show that $a_{2}(\kappa)+3 a_{3}<0$ (since $\left.a_{3}>0\right)$, i.e., $\left[\kappa \delta-(2-d)-\delta(1-d)^{2}\right]+$ $3 \delta(1-d)<0$. The latter is equivalent to the equation

$$
\kappa \leq d\left(\frac{1}{\delta}-1+d\right)+2\left(\frac{1}{\delta}-1\right)(1-d)
$$

which is always true since $\kappa<d\left(\frac{1}{\delta}-1+d\right)$. We conclude that $\widehat{K}^{*}$, and hence $K^{*}=\widehat{K}^{*}-1+d$, is unique.

Having established a unique solution, $K^{*}$, we now solve for the steady state, $\omega^{*}$, from equation (32) and (33). After some algebra, we obtain

$$
\omega^{*}=\frac{\kappa_{0}}{d\left(\frac{1}{\delta}-(1-d)\right)-\kappa} .
$$

We have therefore established a unique pair $\left(K^{*}, \omega^{*}\right)$ with $K^{*}$ as the slope of $\Psi^{*}$ and $\omega^{*}$ as the steady state satisfying (35). As the solution to $F(K+1-d)=0$, notice that $K^{*}$ varies with $\kappa$. We write $K^{*}=B(\kappa)$ to emphasize the dependence on $\kappa$. By the definition of $F$ in (34), it is clear that $B(0)=0$, which then yields an equation for the PA equilibrium $\psi$. As for the hypothetical PE rule, $\Psi$, its solution form is also affine. The coefficients of $\Psi$ can be recovered from $K^{*}$ and $\omega^{*}$ evaluated at their respective solutions. The slope is non-positive and equal to zero iff $\kappa=0$ or $d=1$.

Rest of the proof of Proposition 1. We now turn to Part (ii) of Proposition 1. To prove that convergence to the steady state is monotone, observe that

$$
\Theta^{*}\left(\omega_{t}\right) \equiv(1-d) \omega_{t}+\Psi^{*}\left(\omega_{t}\right)=\left(1-d+K^{*}\right) \omega_{t}+\left(d-K^{*}\right) \omega^{*}
$$

Since $0<K^{*}<d$, if $0<\kappa<d\left(\frac{1}{\delta}-1+d\right)$, then convergence toward the steady state is monotonically increasing if $\omega_{0}<\omega^{*}$, and monotonically decreasing if $\omega_{0}>\omega^{*}$.

The rest of Part (ii) and (iii) can be readily verified from a straight-forward algebra. We omit the details and only give a sketch for the case $\omega_{0}<\omega^{*}$. The comparison of $\Psi^{*}$ and $\Psi\left(i_{0}, \omega\right)$ follows directly from the affine solution and the fact that $f(\mu(\omega))$ is increasing in $\omega$. The comparison of $\psi$ and $\Psi\left(i_{0}, \omega\right)$ follows from the higher slope of $\psi$ and the fact that $\Psi\left(i_{0}, \omega\right)<\psi\left(i_{0}, \omega\right)$, where the latter can be checked easily from the solution. Given Part (ii) 
and the fact that the steady state is higher under PE equilibrium, Part (iii) then follows from the Intermediate Value Theorem.

Rest of the proof of Proposition 2. For Part (ii), an inspection of (36) reveals that $D_{\omega} \Theta^{*}>0$ iff $\widehat{K}^{*}=1-d+K^{*}>0$. Recalling the definition of $F$ in the proof of Proposition 1 , it is clear that $F(0)<0$ and $F(1-d)>0$ if $0>\kappa>-(1-d) / \delta$, and so the zero of $F$ must satisfy $(1-d)>\widehat{K}^{*}>0$. On the other hand, if $-(1-d) / \delta>\kappa>-\frac{1-d}{\delta}-$ $\frac{1+\delta}{1-\delta}\left[(1-d)^{2}+\frac{3+\delta}{1+\delta}(1-d)+\frac{1}{\delta}\right]$, then $F(0)>0$ and $F(-1)<0$, and so the zero of $F$ must satisfy $-1<\widehat{K}^{*}<0$. In the latter case, the Faustian dynamics constitute a dampened cycle whereby, on-path, $\omega_{t}<\omega^{*}$ iff $\omega_{t+1}>\omega^{*}$.

The rest of Part (ii) follows from a similar argument as the corresponding part of Proposition 1 , with the main difference being a negative $\kappa$. Hence we skip the details here.

Proof of Proposition 3. we restrict attention to the case where $\omega_{0}<\omega^{*}$, i.e., the initial state lies below the steady state. The logic when $\omega_{0}>\omega^{*}$ is symmetric.

It is easy to show that the steady state with $\kappa$ is larger than that of $\widetilde{\kappa}$ whenever $\kappa>\widetilde{\kappa}$. Given this and the affine form of equilibrium, to show the final result it suffices to show that $\Psi^{*}\left(\omega_{0}\right)<\widetilde{\Psi}^{*}\left(\omega_{0}\right)$. Let $K^{*}=B(\kappa)$ and $\widetilde{K}^{*}=B(\widetilde{\kappa})$ denote the respective slope of PE equilibria $\Psi^{*}$ and $\widetilde{\Psi}^{*}$. We want to show that,

$$
\left(d-\widetilde{K}^{*}\right) \frac{\widetilde{\kappa}_{0}}{d\left(\frac{1}{\delta}-1+d\right)-\widetilde{\kappa}}+\widetilde{K}^{*} \omega_{0}>\left(d-K^{*}\right) \frac{\kappa_{0}}{d\left(\frac{1}{\delta}-1+d\right)-\kappa}+K^{*} \omega_{0},
$$

which is equivalent to

$$
\frac{d-B(\widetilde{\kappa})}{d\left(\frac{1}{\delta}-1+d\right)-\widetilde{\kappa}}<\frac{B(\kappa)-B(\widetilde{\kappa})}{\kappa-\widetilde{\kappa}} .
$$

In words, the last inequality requires that the slope between the points $(\widetilde{\kappa}, B(\widetilde{\kappa}))$ and $(\kappa, B(\kappa))$ is larger than that between $(\widetilde{\kappa}, B(\widetilde{\kappa}))$ and $\left(d\left(\frac{1}{\delta}-1+d\right), d\right)$ whenever $\kappa>\widetilde{\kappa}$.

To proceed, we need to further characterize the properties of the solution $K^{*}=B(\kappa)$. But since $K^{*}$ and $\widehat{K}^{*}$ differ only by a constant, we examine properties of the solution $\widehat{B}(\kappa) \equiv$ $\widehat{K}^{*}=\widehat{B}(\kappa)+1-d$ below. Recall that the unique solution $\widehat{K}^{*}=\widehat{B}(\kappa)$ is defined implicitly by the equation $F(\widehat{K})=0$. Notice that, at the solution $\widehat{K}^{*}, F\left(\widehat{K}^{*}\right)$ satisfies

$$
\begin{aligned}
F^{\prime}\left(\widehat{K}^{*}\right) & =a_{1}+2 a_{2}(\kappa) \widehat{K}^{*}+3 a_{3}\left(\widehat{K}^{*}\right)^{2}>0 \\
F^{\prime \prime}\left(\widehat{K}^{*}\right) & =2\left(a_{2}(\kappa)+3 a_{3} \widehat{K}^{*}\right)<0 .
\end{aligned}
$$

Since $F^{\prime}(\widehat{B}(\kappa))>0, \widehat{B}(\kappa)$ is continuously differentiable from Implicit Function Theorem. In 
addition, we know that

$$
\widehat{B}^{\prime}(\kappa)=\frac{1-\delta(\widehat{B}(\kappa))^{2}}{a_{1}+2 a_{2}(\kappa) \widehat{B}(\kappa)+3 a_{3}(\widehat{B}(\kappa))^{2}}>0
$$

Take derivative again and after some algebra, we have

$$
\widehat{B}^{\prime \prime}(\kappa)=\frac{-2\left(1-\delta(\widehat{B}(\kappa))^{2}\right)\left[3 \delta a_{3}(\widehat{B}(\kappa))^{3}+3 \delta a_{2}(\kappa)(\widehat{B}(\kappa))^{2}+\left(2 \delta a_{1}+3 a_{3}\right) \widehat{B}(\kappa)+a_{2}(\kappa)\right]}{\left[a_{1}+2 a_{2}(\kappa) \widehat{B}(\kappa)+3 a_{3}(\widehat{B}(\kappa))^{2}\right]^{3}}
$$

Use the fact $a_{0}(\kappa)+a_{1} \widehat{B}(\kappa)+a_{2}(\kappa)(\widehat{B}(\kappa))^{2}+a_{3}(\widehat{B}(\kappa))^{3}=0$ to get

$$
\widehat{B}^{\prime \prime}(\kappa)=\frac{2\left(1-\delta(\widehat{B}(\kappa))^{2}\right)\left(1-\delta\left(1-d^{2}\right)\right)[\widehat{B}(\kappa)-b(\kappa)]}{\left[a_{1}+2 a_{2}(\kappa) \widehat{B}(\kappa)+3 a_{3}(\widehat{B}(\kappa))^{2}\right]^{3}}
$$

where $b(\kappa)=\frac{-\delta d^{2}-2(1-\delta) d+(1-\delta)+4 \delta \kappa}{1-\delta\left(1-d^{2}\right)}$. Consequently, the sign of $\widehat{B}^{\prime \prime}(\kappa)$ is the same as that of $\widehat{B}(\kappa)-b(\kappa)$.

In the following part, we show that there exists a unique $0<\bar{\kappa}<d\left(\frac{1}{\delta}-1+d\right)$ such that (i) $\widehat{B}(\kappa)>b(\kappa)$ for $\kappa<\bar{\kappa}$; (ii) $\widehat{B}(\bar{\kappa})=b(\bar{\kappa})$ for $\kappa=\bar{\kappa}$; (iii) $\widehat{B}(\kappa)<b(\kappa)$ for $\kappa>\bar{\kappa}$. To start with, it is easy to see that $\widehat{B}(0)>b(0)$ and $\widehat{B}\left(d\left(\frac{1}{\delta}-1+d\right)\right) \leq b\left(d\left(\frac{1}{\delta}-1+d\right)\right)$. From the Intermediate Value Theorem there exists a $\bar{\kappa}$ such that $\widehat{B}(\bar{\kappa})=b(\bar{\kappa})$.

Now we show that $\widehat{B}(\kappa)>b(\kappa)$ for $\kappa<\bar{\kappa}$ and $\widehat{B}(\kappa)<b(\kappa)$ for $\kappa>\bar{\kappa}$. To show this, let

$$
G(\kappa)=F(b(\kappa))=a_{3}(b(\kappa))^{3}+a_{2}(\kappa)(b(\kappa))^{2}+a_{1} b(\kappa)+a_{0}(\kappa) .
$$

The derivative of $G(\kappa)$ can be calculated as

$$
G^{\prime}(\kappa)=\left[3 a_{3}(b(\kappa))^{2} b^{\prime}(\kappa)+2 a_{2}(\kappa) b(\kappa) b^{\prime}(\kappa)+\delta(b(\kappa))^{2}+a_{1} b^{\prime}(\kappa)-1\right],
$$

which equals to a quadratic form in $b(\kappa)$,

$$
\begin{aligned}
& \frac{6}{1-\delta\left(1-d^{2}\right)}\left[\frac{1}{2} \delta\left[\delta d^{2}-4 \delta d+1+3 \delta\right](b(\kappa))^{2}\right. \\
& \left.-\delta\left[\delta d^{2}-2(1+\delta) d+(3+\delta)\right] b(\kappa)+\frac{1}{2}\left[\delta d^{2}-4 \delta d+1+3 \delta\right]\right]
\end{aligned}
$$


To see the sign of $G^{\prime}(\kappa)$, first notice that the discriminant for the quadratic equation inside the bracket is

$$
\begin{aligned}
& \delta^{2}\left[\delta d^{2}-2(1+\delta) d+(3+\delta)\right]^{2}-\delta\left[\delta d^{2}-4 \delta d+1+3 \delta\right]^{2} \\
= & \delta(\delta-1)\left(1-\delta(1-d)^{2}\right)<0 .
\end{aligned}
$$

Combine this with the positive quadratic coefficient, i.e., $\delta d^{2}-4 \delta d+1+3 \delta=\delta d^{2}+(1-\delta d)+$ $3 \delta(1-d)>0$, we know that $G^{\prime}(\kappa)>0$ for every $\kappa$. As a result, $G(\kappa)<0$ for $\kappa<\bar{\kappa}$ and $G(\kappa)>0$ for $\kappa>\bar{\kappa}$. Therefore, $\widehat{B}(\kappa)>b(\kappa)$ for $\kappa<\bar{\kappa}$ and $\widehat{B}(\kappa)<b(\kappa)$ for $\kappa>\bar{\kappa}$.

Translating back to our original coefficient, $B(\kappa)$, we have thus established: $B^{\prime}(\kappa)>0$, and $B^{\prime \prime}(\kappa)>0$ for $\kappa<\bar{\kappa}$ and $B^{\prime \prime}(\kappa)<0$ for $\kappa>\bar{\kappa}$. In addition, it is easy to check that $B^{\prime}(0)=\frac{1}{\frac{1}{\delta}-1+d}, B(0)=0$, and $B\left(d\left(\frac{1}{\delta}-1+d\right)\right)=d$. These properties together implies that $B(\kappa) \geq \frac{\kappa}{\frac{1}{\delta}-1+d}, \forall \kappa<d\left(\frac{1}{\delta-1+d}\right)$. Geometrically, $B(\kappa)$ is an increasing function, convex below $\bar{\kappa}$ and concave above $\bar{\kappa}$. In addition, $B(\kappa)$ lies above the line $\frac{\kappa}{\frac{1}{\delta}-1+d}$, with a unique tangent point at $\kappa=0$.

Now we are ready to prove the inequality (37) from a geometric argument. Given the shape of $B(\kappa)$ established earlier, a simple graph shows that the inequality (37) always holds for $\kappa<d\left(\frac{1}{\delta-1+d}\right)$. This concludes the proof of the Proposition.

Proof of Theorem 1. The proof is contained in the Proof of Theorem 3.

Proof of Theorem 2 From definition, $u(i, \omega, a)=\tilde{u}(i, \omega, Q(\omega, a))$. Use this fact to replace $u$ with $\tilde{u}$ in equation (18.a), after some algebra it follows that

$$
R\left(i, \omega_{t}, \Psi^{*}\right)=D_{\omega_{t}} \tilde{u}\left(i, \omega_{t}, \Theta^{*}\left(\omega_{t}\right)\right),
$$

where $\Theta^{*}\left(\omega_{t}\right)=Q\left(\omega_{t}, \Psi^{*}\left(\omega_{t}\right)\right)$ for any $\Psi^{*}$ (including permanent authority equilibrium $\psi(\omega)$ ). From (A1), $R\left(i, \omega_{t}, \Psi^{*}\left(\omega_{t}\right)\right)>R\left(i, \omega_{t}, \psi\left(\omega_{t}\right)\right)$ if and only if $Q\left(\omega_{t}, \Psi^{*}\left(\omega_{t}\right)\right)>Q\left(\omega_{t}, \psi\left(\omega_{t}\right)\right)$. From the monotonicity of $Q(\omega, a)$ in $a, Q\left(\omega_{t}, \Psi^{*}\left(\omega_{t}\right)\right)>Q\left(\omega_{t}, \psi\left(\omega_{t}\right)\right)$ if and only if $\Psi^{*}\left(\omega_{t}\right)>\psi\left(\omega_{t}\right)$. This concludes the proof.

Proof of Theorem 3 For any arbitrary, smooth, strict supermodular continuation value $U(i, \omega)$, define

$$
H\left(i, \omega_{t}, a_{t}, U\right)=u\left(i, \omega_{t}, a_{t}\right)+\delta U\left(i, Q\left(\omega_{t}, a_{t}\right)\right) .
$$

$H\left(i, \omega_{t}, a_{t}, U\right)$ is the payoff function of a citizen-type $i$ in state $\omega_{t}$ when his continuation is defined by $U\left(i, \omega_{t+1}\right)$. Let $\Psi(i, \omega, U) \in \arg \max _{a} H\left(i, \omega_{t}, a_{t}, U\right)$, and let $\Psi^{*}(\omega, U)=\Psi(\mu(\omega), \omega, U)$. 
To prove the monotonicity property, it is more convenient to work with a related representation as

$$
\widetilde{H}\left(i, \omega_{t}, \omega_{t+1}, U\right)=\tilde{u}\left(i, \omega_{t}, \omega_{t+1}\right)+\delta U\left(i, \omega_{t+1}\right),
$$

where $\tilde{u}\left(i, \omega_{t}, \omega_{t+1}\right)$ is defined in Assumption (A1). Define $\Theta(i, \omega, U) \in \arg \max _{\omega_{t+1}} \tilde{H}\left(i, \omega_{t}, \omega_{t+1}, U\right)$ and $\Theta^{*}(\omega, U)=\Theta(\mu(\omega), \omega, U)$.

From the definition, it is immediate that $H\left(i, \omega_{t}, a_{t}, U\right)=\widetilde{H}\left(i, \omega_{t}, Q\left(\omega_{t}, a_{t}\right), U\right), \Theta(i, \omega, U)=$ $Q(\omega, \Psi(i, \omega, U))$ and $\Theta^{*}(\omega, U)=Q\left(\omega, \Psi^{*}(\mu(\omega), \omega, U)\right)$. In addition, since $D_{a} Q(\omega, a)>0$, $H\left(i, \omega_{t}, a_{t}, U\right)$ is supermodular in $(i, a)$ if and only if $\widetilde{H}\left(i, \omega_{t}, \omega_{t+1}, U\right)$ is supermodular in $\left(i, \omega_{t+1}\right)$.

We now proceed with the proof. From Assumption (A1), $\widetilde{H}\left(i, \omega_{t}, \omega_{t+1}, U\right)$ is smooth, supermodular in $\left(i, \omega_{t}, \omega_{t+1}\right)$ and strictly supermodular in $\left(i, \omega_{t+1}\right)$. By Topkis Monotonicity Theorem, $\Theta\left(i, \omega_{t}, U\right)$ is nondecreasing in $\left(i, \omega_{t}\right)$ and strictly increasing in $i$ for any $U$. Hence, we have shown that $\Theta^{*}(\omega, U)=\Theta(\mu(\omega), \omega, U)$ is increasing in $\omega$. Combined with Assumption (A1), this implies that

$$
D_{i} D_{\omega} \widetilde{H}\left(i, \omega, \Theta^{*}(\omega, U), U\right)=D_{i} D_{\omega} \tilde{u}+\delta D_{\omega} \Theta^{*} \cdot D_{i} D_{\omega^{\prime}} U\left(i, \omega^{\prime}\right)>0
$$

As a result, the map $U \mapsto H\left(i, \omega, \Theta^{*}(\omega, U), U\right)$ maps from functions with strictly increasing differences in $i$ and $\omega$ to functions of the same.

Consider, then the finite horizon PE equilibrium with horizon $T$. Let $\Theta_{T}=\left\{\Theta_{t, T}^{*}\right\}_{t=1}^{T}$ denote the PE equilibrium transition in the $T$-period model, and let $U_{t, T}$ denote the value function in each period $t$. Notice that $U_{T, T}=\tilde{u}$ which satisfies strictly increasing differences in $(i, \omega)$ by Assumption (A1). ${ }^{24}$ A simple backward induction argument establishes that $U_{t, T}$ satisfies strictly increasing differences for all $t$. From the definition of the Smooth Limit Equilibrium, $\left\|U_{t, T}-V\left(\cdot ; \Theta^{*}\right)\right\| \rightarrow 0$ as $T \rightarrow \infty$, and $V\left(\cdot ; \Theta^{*}\right)$, the infinite horizon PE equilibrium continuation value, has increasing differences in $i$ and $\omega$. In fact, by repeating the step of the previous paragraph, it follows that $V\left(\cdot ; \Theta^{*}\right)$ must have strictly increasing differences in $i$ and $\omega$.

Consequently, the solution $\Theta(i, \omega)$ must be strictly increasing in $i$, and so $\Theta^{*}$ must be strictly increasing in $\omega$. This completes the proof of monotonicity of $\Theta^{*}$.

This argument established $\Theta^{*}\left(\omega_{t}\right)=\Theta\left(\mu\left(\omega_{t}\right), \omega_{t}\right)>\Theta\left(i_{0}, \omega_{t}\right)$ for all $\omega_{t}>\omega_{0}$, or by definition

$$
Q\left(\omega_{t}, \Psi^{*}\left(\omega_{t}\right)\right)=\Theta^{*}\left(\omega_{t}\right)>\Theta\left(i_{0}, \omega_{t}\right)=Q\left(\omega_{t}, \Psi\left(i_{0}, \omega_{t}\right)\right) .
$$

From the monotonicity of $Q(\omega, a)$ in $a$, we have $\Psi^{*}\left(\omega_{t}\right)>\Psi\left(i_{0}, \omega_{t}\right)$.

\footnotetext{
${ }^{24}$ In the last period $T, \underline{\omega}$ is chosen by the decision maker since there is no future return to the costly investment.
} 
Proof of Theorem 4. From definition, $\Theta(\omega)=Q\left(\omega, \Psi^{*}(\omega)\right)$, with the derivative

$$
D_{\omega} \Theta(\omega)=D_{\omega} Q+D_{a} Q D_{\omega} \Psi^{*} .
$$

Combine equation (42) and (18.b) to get

$$
P\left(i, \omega_{t+1} ; \Psi^{*}\right)=\left(D_{a_{t+1}} Q\right)^{-1} \cdot D_{\omega_{t+1}} \Theta^{*} \cdot \Delta\left(i, \omega_{t+1} ; \Psi^{*}\right) .
$$

We know that, $D_{a_{t+1}} Q>0$ and from the proof of Theorem 3, $D_{\omega_{t+1}} \Theta^{*}>0$. Therefore, $P\left(i, \omega_{t+1} ; \Psi^{*}\right)<0$ follows if and only if $\Delta\left(i, \omega_{t+1} ; \Psi^{*}\right)<0$.

Let $V^{*}(i, \omega) \equiv V\left(i, \omega ; \Psi^{*}\right)$ be the equilibrium continuation value. Using the definition of $H$ in (39) and that of the distortion function $\Delta$ in (14), we have

$$
\left.D_{a_{t+1}} H\left(i_{t}, \omega_{t+1}, \Psi^{*}\left(\omega_{t+1}\right)\right), V^{*}\right)=\Delta\left(i_{t}, \omega_{t+1} ; \Psi^{*}\right)
$$

Using the Proof of Theorem 3, which establishes strictly increasing differences of $H$ in $i$ and $a$, it follows that $\Delta\left(i, \omega_{t+1} ; \Psi^{*}\right)$ is increasing in $i$. It implies that whenever $i<i_{t+1}=\mu\left(\omega_{t+1}\right)$, then

$$
\Delta\left(i, \omega_{t+1} ; \Psi^{*}\right)<\Delta\left(i_{t+1}, \omega_{t+1} ; \Psi^{*}\right)=0
$$

where the latter equality follows from the type $i_{t+1}$ 's first order condition in state $\omega_{t+1}$. This concludes the proof.

Proof of Theorem 5. Part (i). The permanent authority case follows from the standard argument. For the PE equilibrium, the necessity part is obvious. To see the sufficiency, notice that the equation coincides with the steady state equation of the PA equilibrium with $i_{0}=\mu\left(\omega^{*}\right)$. Since a PA decision maker faces fewer constraints than a PE one, if a PA authority decides to keep the state constant, it must be the optimal choice of a PE authority.

Part (ii) is obvious given Part (i).

We now prove Part (iii), i.e., $\omega^{\circ}<\omega^{*}$ if and only if $\omega_{0}<\omega^{*}$. Consider $i_{0}=\mu\left(\omega_{0}\right)$ and $i^{*}=\mu\left(\omega^{*}\right)$. From the strict increasing difference between $i$ and $\left(\omega_{t}, \omega_{t+1}\right)$, for each $\left(\omega_{t}, \omega_{t+1}, \omega_{t+2}\right)$

$$
\begin{aligned}
& D_{\omega_{t+1}} \widetilde{u}\left(i^{*}, \omega_{t}, \omega_{t+1}\right)+\delta D_{\omega_{t+1}} \widetilde{u}\left(i^{*}, \omega_{t+1}, \omega_{t+2}\right) \\
> & D_{\omega_{t+1}} \widetilde{u}\left(i_{0}, \omega_{t}, \omega_{t+1}\right)+\delta D_{\omega_{t+1}} \widetilde{u}\left(i_{0}, \omega_{t+1}, \omega_{t+2}\right),
\end{aligned}
$$

if and only if $i_{0}<i^{*}$. Evaluate at $\left(\omega_{t}, \omega_{t+1}, \omega_{t+2}\right)=\left(\omega^{\circ}, \omega^{\circ}, \omega^{\circ}\right)$ to get

$$
\begin{aligned}
& D_{\omega_{t+1}} \widetilde{u}\left(i^{*}, \omega^{\circ}, \omega^{\circ}\right)+\delta D_{\omega_{t+1}} \widetilde{u}\left(i^{*}, \omega^{\circ}, \omega^{\circ}\right) \\
> & D_{\omega_{t+1}} \widetilde{u}\left(i_{0}, \omega^{\circ}, \omega^{\circ}\right)+\delta D_{\omega_{t+1}} \widetilde{u}\left(i_{0}, \omega^{\circ}, \omega^{\circ}\right) \\
= & 0 \\
= & D_{\omega_{t+1}} \widetilde{u}\left(i^{*}, \omega^{*}, \omega^{*}\right)+\delta D_{\omega_{t+1}} \widetilde{u}\left(i^{*}, \omega^{*}, \omega^{*}\right),
\end{aligned}
$$


if and only if $i^{*}>i_{0}$. Since $D_{\omega_{t+1}} \widetilde{u}(i, \omega, \omega)+\delta D_{\omega_{t+1}} \widetilde{u}(i, \omega, \omega)$ is decreasing in $\omega$, the inequality holds if and only if $\omega^{\circ}<\omega^{*}$. To summarize, we have just proven that $\omega^{\circ}<\omega^{*}$ if and only if $i_{0}<i^{*}$, i.e., $\omega_{0}<\omega^{*}$.

\section{References}

[1] Acemoglu, D., S. Johnson, and J. Robinson (2005), "Institutions as the Fundamental Cause of Long-Run Growth," Economic Growth, P. Aghion and S. Durlauf, eds., North Holland.

[2] Acemoglu, D. and J. Robinson (2000), "Why Did the West Extend the Franchise? Democracy, Inequality and Growth in Historical Perspective," Quarterly Journal of Economics, 115: $1167-1199$.

[3] Acemoglu, D. and J. Robinson (2001), "A Theory of Political Transitions," American Economic Review, 91: 938-963.

[4] Acemoglu, D. and J. Robinson (2006), Economic Origins of Dictatorship and Democracy, Cambridge University Press.

[5] Acemoglu, D. and J. Robinson (2008), "Persistence of Powers, Elites and Institutions," American Economic Review, 98: 267-293.

[6] Alesina, A. and D. Rodrik (1994), "Distributive Politics and Economic Growth," Quarterly Journal of Economics, 109: 465 - 490.

[7] Alesina, A. and G. Tabellini (1990), "A Positive Theory of Fiscal Deficits and Government Debts," Review of Economic Studies,57:403-414.

[8] Amador, M. (2003), "A Political Model of Sovereign Debt Repayment," mimeo, Stanford Universty.

[9] Amir, R. (1996), Continuous Stochastic Games of Capital Accumulation with Convex Transitions, Games and Economic Behavior, 16: 111-31.

[10] Azzimonti, M. (2005), "On the Dynamic Inefficiency of Governments," mimeo, University of Iowa.

[11] Barbera, S., M. Maschler, and S. Shalev (2001), "Voting for voters: A model of electoral evolution," Games and Economic Behavior, 37: 40-78.

[12] Bartels, L. (2008), Unequal Democracy: The Political Economy of the New Gilded Age, Princeton, NJ: Princeton University Press.

[13] Basar, J. and Olsder (1982), Dynamic Non-cooperative Game Theory, Academic Press, London/New York.

[14] Battaglini, M. and S. Coate (2007), "Inefficiency in Legislative Policy-Making: A Dynamic Analysis," American Economic Review, 97 (1): 118-149.

[15] Battaglini, M. and S. Coate (2008), "A Dynamic Theory of Public Spending, Taxation and Debt," American Economic Review, 98: 201-236. 
[16] Benabou, R. (2000), "Unequal Societies: Income Distribution and the Social Contract," American Economic Review, 90(1): 96-129.

[17] Bertola, G. (1993), "Factor Shares and Savings in Endogenous Growth," American Economic Review, 83: 1184 - 1210.

[18] Besley, T. and S. Coate (1998), "Sources of Inefficiency in a Representative Democracy: A Dynamic Analysis," American Economic Review, 88: 139-156.

[19] Bhaskar, V. and F. Vega-Redondo (2002), "Asynchronous Choice and Markov Equilibria," Journal of Economic Theory, 103: 334-350.

[20] Black, E. and M. Black (2002), The Rise of Southern Republicans, Cambridge, MA: Harvard University Press.

[21] Bourguignon, F., and T. Verdier (2000), "Oligarchy, Democracy, Inequality and Growth," Journal of Development Economics, 62: 287-313.

[22] Campante, F. (2007), "Redistribution in a Model of Voting and Campaign Contributions," mimeo, Harvard University.

[23] Cervellati, M, P. Fortunato, and U. Sunde (2006), "Consensual and Conflictual Democratization," mimeo.

[24] Curtat (1996), "Markov Equilibria in Stochastic Games with Complementarities, Games and Economic Behavior, 17: 177-99.

[25] Dolmas, J. and G.W. Huffman (2004), "On the Political Economy of Immigration and Income Redistribution," International Economic Review,45(4):1129-1168.

[26] Finer, S.E. (1997), The History of Government, Oxford University Press, Oxford, UK.

[27] Gans, J. and M. Smart (1996), "Majority voting with single-crossing preferences," Journal of Public Economics, 59: 219-237.

[28] von Goethe, J.W. (1932), Faust: A Tragedy In Two Parts, London, Oxford Univ Press Humphrey Milford. Translated in the original metres by Bayard Taylor.

[29] Grandmont, J.-M. (1978): "Intermediate Preferences and the Majority Rule," Econometrica, 46(2): 317-330.

[30] Harris, C. and D. Laibson (2001), "Dynamic Choices of Hyperbolic Consumers," Econometrica, 69, 935-957.

[31] Hassler, J., P. Krusell, K. Storlesletten, and F. Zilibotti (2005), "The Dynamics of Government," Journal of Monetary Economics 52: 1331-1358.

[32] Hassler, J., J.V. Rodriguez Mora, K. Storlesletten, and F. Zilibotti (2003), "The Survival of the Welfare State," American Economic Review 93: 87-112.

[33] Horst, U. (2005), "Stationary Equilibria in Discounted Stochastic Games with Weakly Interacting Players, Games and Economic Behavior, 51: 83-108. 
[34] Husted, T. and L. Kenny (1997), "The Effect of the Expansion of the Voting Franchise on the Size of Government," Journal of Political Economy, 108: 54-82.

[35] Jack, W. and R. Lagunoff (2004), "Dynamic Enfranchisement," Unpublished version to (2006a): www9.georgetown.edu/faculty/lagunofr/franch10.pdf

[36] Jack, W. and R. Lagunoff (2006a), "Dynamic Enfranchisement," Journal of Public Economics, 90: 551-572.

[37] Jack, W. and R. Lagunoff (2006b), "Social Conflict and Gradual Political Succession: An Illustrative Model," Scandinavian Journal of Economics, 108: 703-25.

[38] Judd, K. (2004), "Existence, Uniqueness, and Computatational Theory for Time Consistent Equilibria: A Hyperbolic Discounting Example," mimeo, Hoover Institution.

[39] Klein, P., P. Krusell, and J.-V. Ríos-Rull (2008), "Time Consistent Public Policy," Review of Economic Studies, 75: 789-808.

[40] Krusell, P. and J.-V. Rios -Rull (1999), "On the Size of U.S. Government: Political Economy in the Neoclassical Growth Model," American Economic Review, 89: 11561181.

[41] Krussell, P., V. Quadrini, and J-V Rios-Rull (1996), "Are Consumption Taxes Really Better than Income Taxes," Journal of Monetary Economics 37: 475-503.

[42] Krusell, P., V. Quadrini, and J.-V. Ríos -Rull (1997), "Politico-Economic Equilibrium and Economic Growth," Journal of Economic Dynamics and Control, 21: 243-72.

[43] Krusell, P. and A. Smith (2003), "Consumption-Savings Decisions with Quasi-Geometric Discounting," Econometrica, 71: 365-375.

[44] Krusell, P., B. Kuruscu, and A. Smith (2002) "Equilibrium Welfare and Government Policy with Quasi-Geometric Discounting", Journal of Economic Theory, 105: 42-72.

[45] Lagunoff (2009) "Dynamic Stability and Reform of Political Institutions," Games and Economic Behavior, forthcoming.

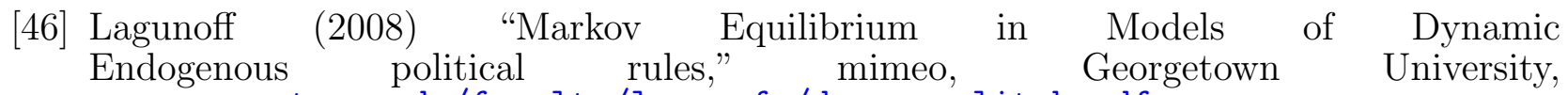
ww. georgetown. edu/faculty/lagunofr/dynam-polit-b.pdf

[47] Laibson, D. (1997), "Golden Eggs and Hypobolic Discounting," Quarterly Journal of Economics, 112, 443-477.

[48] Lott, J. and L. Kenny (1999) "Did Womens Suffrage Change the Size and Scope of Government?" Journal of Political Economy 107: 1163-1198.

[49] Milesi-Ferretti, G-M and E. Spolaore (1994), "How Cynical can an Incumbent Be? Strategic Policy in a Model of Government Spending, Journal of Public Economics, 55: 121-140.

[50] Novak, A.S. (2007), "On Stochastic Games in Economics," Mathematical Methods of Operations Research, forthcoming. 
[51] Ortega, F. (2005), "Immigration Quotas and Skill Upgrading," Journal of Public Economics, 89: 1841-1863.

[52] Peltzman, S. (1980), "The Growth of Government." Journal of Law and Economics, 23: 209-288.

[53] Persson, T. and G. Tabellini (2000), Political Economics, Cambridge, MA: MIT Press.

[54] Persson, T. and L. Svensson (1989), "Why a Stubborn Conservative would Run a Deficit: Policy with Time-Inconsistent Preferences," Quarterly Journal of Economics, 104: 325345.

[55] Persson, T. and G. Tabellini (2007), "Democratic Capital: The Nexus of Political and Economic Change," American Economic Journal: Macroeconomics,forthcoming.

[56] Roberts, K. (1998), "Dynamic Voting in Clubs," mimeo, STICERD/Theoretical Economics Discussion Paper, LSE.

[57] Roberts, K. (1999), "Voting in Organizations and Endogenous Hysteresis," mimeo, Nuffield College, Oxford.

[58] Rothstein, P. (1990), "Order Restricted Preferences and Majority Rule," Social Choice and Welfare, 7: 331-42.

[59] Rodriguez, D. and B. Weingast (2006), "The Untold Story of the 1964 Civil Rights Act: How the GOP Helped the Democrats Destroy the Solid South," mimeo, July.

[60] Stewart, J.G. (1997), "The Senate and Civil Rights," in The Civil Rights Act of 1964: The Passage of the Law That Ended Racial Segregation, R. Loevy, edt., State University of New York Press, New York.

[61] Tichenor, D. (2002), Dividing Lines: The Politics of Immigration Control in America, Princeton University Press, Princeton, NJ. 